\title{
Assessment of Nonobtrusive Methods for Verifying Demonstrably Safe Reactor Response
}

Integral Fast Reactor Integral Fast Reactor Integral Fast Reactor Integral Fast Reactor by R. B. Vilim and S. E. Aumeier Integral Fast Reactor Integral Fast Reactor Integral Fast Reactor Integral Fast Reactor Integral Fast. Reactor Integral Fast Reactor Integral Fast Reactor Integral Fast Reactor Integral Fast Reactor Integral Fast Reactor Integral Fast Reactor Integral Fast Reactor Integral Fast Reactor

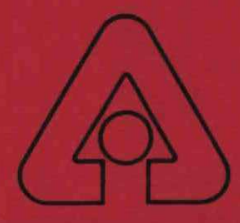

Argonne National Laboratory, Argonne, Illinois 60439 operated by The University of Chicago

for the United States Department of Energy under Contract W-31-109-Eng-38

IFR Technical Memorandum

Results reported in the IFR-TM sories of

memoranda frequently aro proliminary and

subject to revision. Consequently they should

not be quated of reforenced.

\section{NO ACCESS RESTRICTIONS}

This document is not considered OUO-Applied Technology. It was reviewed for Export Controlled Information and found to be suitable for unlimited access and reproduction.

This label reflects Applied Technology instructions issued April 13,

2006, by the the Department of Energy Office of Nuclear Energy.

Additional guidance has also been provided by DOE in 2016 and 2018 memos. as well as from NNSA.
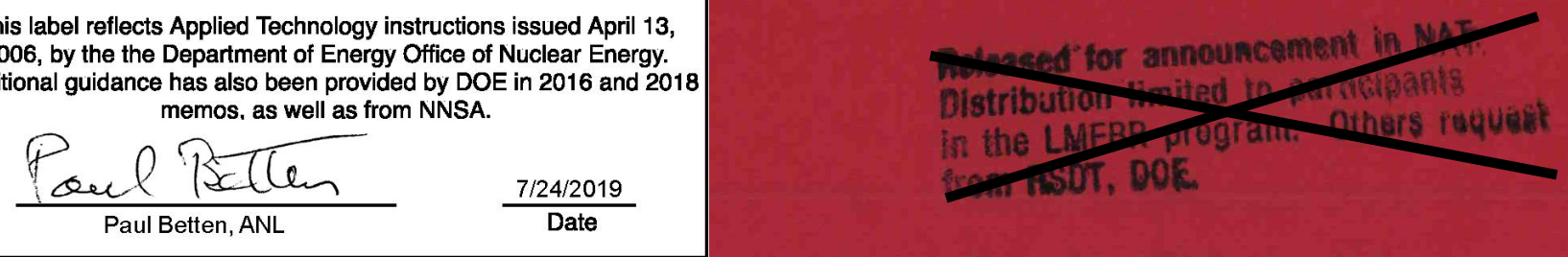
Argonne National Laboratory, with facilities in the states of Illinois and Idaho, is owned by the United States government, and operated by The University of Chicago under the provisions of a contract with the Department of Energy.

\section{DISCLAIMER}

This report was prepared as an account of work sponsored by an agency of the United States Government. Neither the United States Government nor any agency thereof, nor any of their employees, makes any warranty, express or implied, or assumes any legal liability or responsibility for the accuracy, completeness, or usefulness of any information, apparatus, product, or process disclosed, or represents that its use would not infringe privately owned rights. Reference herein to any specific commercial product, process, or service by trade name, trademark, manufacturer, or otherwise, does not necessarily constitute or imply its endorsement, recommendation, or favoring by the United States Government or any agency thereof. The views and opinions of authors expressed herein do not necessarily state or reflect those of the United States Government or any agency thereof. 


\section{DISCLAIMER}

This report was prepared as an account of work sponsored by an agency of the United States Government. Neither the United States Government nor any agency Thereof, nor any of their employees, makes any warranty, express or implied, or assumes any legal liability or responsibility for the accuracy, completeness, or usefulness of any information, apparatus, product, or process disclosed, or represents that its use would not infringe privately owned rights. Reference herein to any specific commercial product, process, or service by trade name, trademark, manufacturer, or otherwise does not necessarily constitute or imply its endorsement, recommendation, or favoring by the United States Government or any agency thereof. The views and opinions of authors expressed herein do not necessarily state or reflect those of the United States Government or any agency thereof. 


\section{DISCLAIMER}

Portions of this document may be illegible in electronic image products. Images are produced from the best available original document. 


\section{ASSESSMENT OF NONOBTRUSIVE METHODS FOR VERIFYING DEMONSTRABLY SAFE REACTOR RESPONSE}

by

R. B. Vilim and S. E. Aumeier* Reactor Analysis Division Argonne National Laboratory 9700 South Cass Avenue Argonne, IL 60439

IFR TECHNICAL MEMORANDUM NO. 224

Results reported in the IFR-TM series of memoranda frequently are preliminary and subject to revision. Consequently they should not be quoted or referenced.

\section{APPLIED TECHNOLOGY}

Any further distribution by any holder of this document or data therein to third parties representing foreign interests, foreigh governments, foreign companies, and foreign subsidiaries or foreign divisions of U.S. companies shall be approved by the Associate Deputy Assistant Secretary for Reactor Systems, Development, and Fechnology, U.S. Department of Energy. Further, foreign party release-may require DOE approval pursuant to Federal Regutation 10 CFR Part 810, andfor may be subject to Seetion 127 of the Atomic Energy Act.

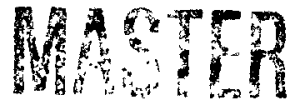

*University of Michigan, Ann Arbor, Michigan. 

ABSTRACT $\ldots \ldots \ldots \ldots \ldots \ldots \ldots \ldots \ldots \ldots \ldots \ldots \ldots \ldots \ldots \ldots$

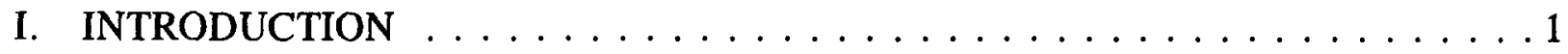

II. PHYSICS AND MODELS $\ldots \ldots \ldots \ldots \ldots \ldots \ldots \ldots \ldots \ldots$

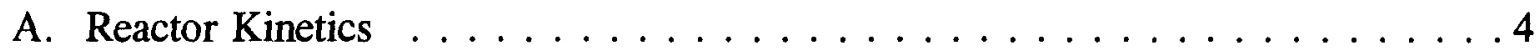

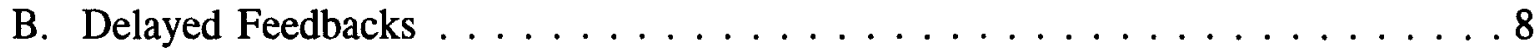

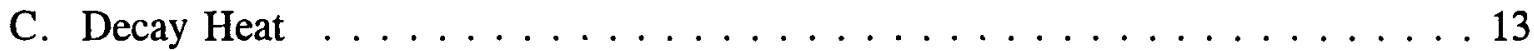

III. PARAMETERS AND PERTURBATIONS . . . . . . . . . . . . . . . . . . 14

A. Kinetics Parameters at Startup . . . . . . . . . . . . . . . . 14

B. Integral Feedback Parameters at Startup . . . . . . . . . . . . . 15

C. Modifications for Parameters at Midcycle . . . . . . . . . . . . . 15

IV. IDENTIFICATION OF THE REACTOR SYSTEM . . . . . . . . . . . . 18

A. Nonlinear Probabilistic Simulation Model . . . . . . . . . . . . . . 20

B. Parameter Estimation by Maximizing the Likelihood Function $\ldots \ldots \ldots 21$

C. Predictions Using the Probabilistic Model . . . . . . . . . . . . 22

D. Model Validation in Terms of Residuals . . . . . . . . . . . . . . . 24

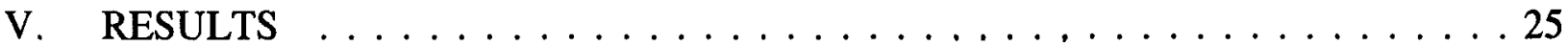

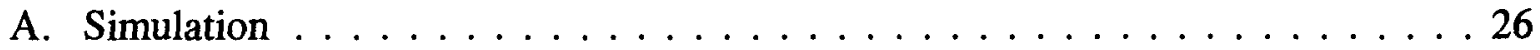

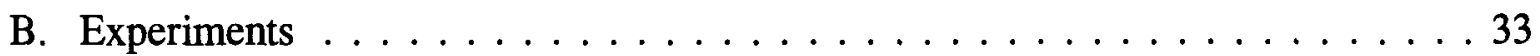

1. Relative Delayed-neutron Fractions $\ldots \ldots \ldots \ldots \ldots \ldots \ldots$

2. Differential Rod Worths . . . . . . . . . . . . . . . 36

3. Integral Feedback Parameters from Obtrusive Perturbations . . . . . . 38

4. Integral Feedback Parameters from Nonobtrusive Perturbations . . . . . . 40

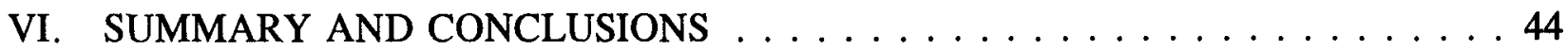

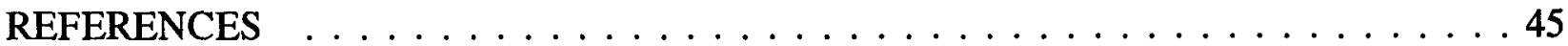

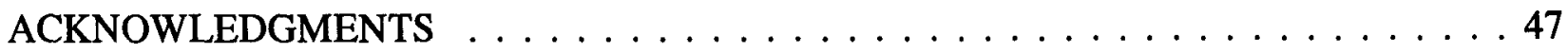

APPENDIX A. LIKELIHOOD FUNCTION FOR A NONLINEAR STOCHASTIC SYSTEM $\ldots \ldots \ldots \ldots \ldots \ldots$

APPENDIX B. ASYMPTOTIC PROPERTIES OF THE MEASUREMENT RESIDUAL MATRICES $\ldots \ldots \ldots \ldots \ldots \ldots \ldots \ldots \ldots \ldots \ldots$ 


\section{LIST OF FIGURES}

$\underline{\text { Page }}$

1. Bowing Reactivity as a Function of Power-to-flow Ratio . . . . . . . . . . . 12

2. Flux Die-away from Simulated Rod Drop of -20 Cents $\ldots \ldots \ldots \ldots$. . . . 27

3. Simulated Reactor Flowrate Perturbation . . . . . . . . . . . . . . . . 29

4. Simulated Rod Reactivity Perturbation $\ldots \ldots \ldots \ldots \ldots \ldots \ldots \ldots$

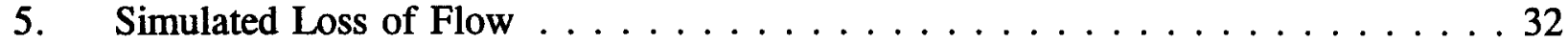

6. Simulated Rod Reactivity Insertion $\ldots \ldots \ldots \ldots \ldots \ldots \ldots$

7. Flux Die-away from Rod Drop Experiment in EBR-II $\ldots \ldots \ldots \ldots \ldots$

8. Differential Rod Worths Measured in EBR-II . . . . . . . . . . . . . . . 37

9. Reactor Flowrate Perturbation Experiment in EBR-II . . . . . . . . . . . . 41

10. Control Rod Position Perturbation Experiment in EBR-II . . . . . . . . . . . 42

11. Reactor Inlet Temperature Perturbation Experiment in EBR-II . . . . . . . . . 43 


\section{LIST OF TABLES}

$\underline{\text { Page }}$

I. Typical Time Constants for a Metal Fueled Liquid Metal Reactor . . . . . . . . . 9

II. Reactor Forcing Function Perturbations at Startup and Parameters Controlling Response . . . . . . . . . . . . . . . . 16

III. Reactor Forcing Function Perturbations at Midcycle and Parameters Controlling Response . . . . . . . . . . . . . . . . . . . . 19

IV. Properties of Noise Added to Simulation Data . . . . . . . . . . . . . . . 27

V. Relative Delayed-neutron Fractions for a Simulated Rod Drop

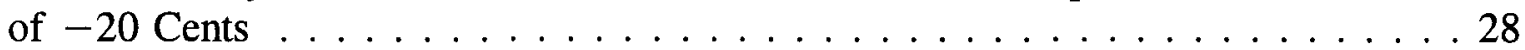

VI. Summary of Experiments Performed at Start of Runs 160A and 161A . . . . 34

VII. Relative Delayed-neutron Fractions for Rod Drop of -18 Cents in EBR-II 36

VIII. Reactor Data for a Large Flowrate Change to Measure B and A in EBR-II 
-vi- 


\title{
ASSESSMENT OF NONOBTRUSIVE METHODS FOR VERIFYING DEMONSTRABLY SAFE REACTOR RESPONSE
}

by

\author{
R. B. Vilim and S. E. Aumeier
}

\begin{abstract}
This report examines methods for determining whether a reactor designed to be demonstrably safe is, in fact, so. A reactor is demonstrably safe if plant tests show that the severest accidents do not lead to core damage. A special class of reactors, those where the same physical mechanisms that control accident behavior also control normal operating behavior, allow for this property to be tested for at normal operation. A method is developed for such reactors to verify safety by performing perturbation tests during normal operation. Results of its application to the EBR-II reactor using computer simulations and actual experiments are described. An assessment of the prospects for accurately predicting the unprotected upset behavior of an IFR is made.
\end{abstract}


-viii- 


\section{INTRODUCTION}

Advanced so-called passively safe reactor concepts have emerged in the past few years. These concepts, to varying degrees, make use of intrinsic design features to improve safety over what is achievable using active systems alone. Such features have the potential to perform more reliably since they do not depend on electromechanical components but only on the natural laws governing heat, fluid flow and neutron production. In addition to being designed to be passively safe, it has also been argued that these reactors must be designed to be demonstrably safe if they are to have a role in U. S. energy supply.[1,2] That is, one must be able to demonstrate through full-scale tests on the integrated power plant that the reactor will survive the very severest of tests. Such tests would provide incontrovertible evidence of the safety of a design to a licensing body or a sceptical public.

We put forth that there are two classes of tests needed to demonstrate safety. The first class provides proof of principle. While design calculations may show that the plant is safe, only by conducting the severest accidents on the actual plant can this be demonstrated unequivocally. The accidents that need to be performed will have been identified in the early stages of the plant design when the integration of passive safety systems was explicitly treated.[3] While this first class of tests can provide irrefutable evidence for the safety of the design, a second class of tests needs to be performed on each operating copy of the reactor design. The goal of this second class of tests is to detect those events that cannot be detected in the first class--anomalies that develop after prolonged operation or improper assembly of a copy. These tests must be performed periodically. This second class of tests is the subject of this report; the first class was addressed previously.[3,4]

The purpose of this report is to assess a methodology for performing this second class of tests for a specialized class of reactors. This class consists of those reactors where accident behavior is controlled by the same mechanisms that control normal operation. For this class, the physics of normal operation can be characterized through perturbations of the reactor forcing functions without disrupting normal operation. This characterization is then used as a basis for predicting upset behavior. The prospects for using this methodology to predict the upset 
behavior of an Integral Fast Reactor (IFR) is investigated. In the IFR, the pool plant layout, the use of metallic fuel and a high internal conversion ratio provide for the inherent processes that bring the core to a safe condition for virtually all off-normal conditions, including operator errors and control system failures.[3]

The characterization of the plant physics through perturbation tests is a problem of system identification. Mathematical models for the process of interest cannot be completely specified so a model has to be identified using actual observations of the process output. There are four steps. First, a model structure for the physical system is assumed based on a general consideration of the physical laws. Second, forcing functions are perturbed in the plant to determine values for parameters appearing in the model of the system. Third, the validity of this identified model is tested by checking for statistical consistency between the model and the measurements. The identified model comprises a measured basis from which the system response to forcing functions can be predicted. Fourth, an envelope that bounds the system response and whose width reflects the magnitude of the model uncertainty is computed for the forcing functions for which we wish to make predictions of how the system will respond. The forcing functions of interest are those associated with the five accident classes that bound the response of the reactor for all unprotected upsets.[3] In a reactor many time constants are simultaneously present, but because these forcing functions do not excite some of the faster time constants, not all are considered. For this reason this work does not provide a characterization of reactor stability.

The prediction of the passive response of a reactor for all encompassing accident classes based on perturbation tests at normal operation does not appear to have been previously addressed in the literature. Perhaps this is because the IFR is unlike any other reactor in that its safety posture is predicated on the fact that the physics governing upset response are also those that govern normal at power operation. Other passively safe reactor types require a realignment or discrete change of state (opening of a valve, overflowing of a reservoir or a momentum imbalance in a flow network) to invoke the physics for off-normal conditions. 
Generally this realignment is forbidden during normal operation so the physics of off-normal operation cannot be tested for.

The body of this report consists of four parts. The first part presents the physics of operation of the IFR and establishes the level of model detail necessary to adequately describe off-normal behavior. Models of the reactor, of the thermal hydraulics feedback and of the decay heat are developed. The second part establishes a mapping between individual reactor parameters and the reactor forcing function perturbations needed to determine their values. The third part presents a methodology to identify an uncertain dynamic system which is the framework in which we view the reactor. The approach is general in nature and is aimed at developing mathematical tools. The fourth part consists of results obtained from application of the models and methodology for both simulations of and experiments performed on the EBR-II reactor.

\section{PHYSICS AND MODELS}

The physics of operation and safety of an IFR can be represented by some very simple models. A low-order dynamic model with a few model parameters captures the time behavior with surprising accuracy. This is rather fortunate. A fact that quickly becomes evident when applying system identification techniques is that model complexity can lead to insurmountable problems. In particular, the number of parameters to be identified goes up with model complexity while the ability to resolve these parameters decreases. Thus, there is an incentive to limit the model to the barest of elements.

The minimum model is determined by three things: the spatial extent of the system to be identified, the regimes of physics that occur during operation and the resolution needed. Because the accident behavior of the forcing functions driving the reactor--inlet temperature, external reactivity (control rods) and flowrate--are known a priori,[3] identification can be limited to the reactor. Second, because the reactor is designed to passively maintain all process variables so that there will be no change of phase of structural materials or coolant, the regimes 
of physics that occur during accident conditions are limited to those that occur during normal operation. Third, spatial resolution is limited to the global power and the mixed mean outlet temperature so as to ensure that the average reactor conditions remain below failure limits. Temporal resolution is limited to accurate prediction of the peak and asymptotic temperatures for five accidents[3] for comparison with failure limits.

\section{A. Reactor Kinetics}

The point kinetics equations provide an accurate means for calculating fission power in a liquid metal reactor. Because of the hard spectrum, the neutron mean free path is large and the flux is transparent to fission product poisons. As a result, the flux shape tends to be preserved with respect to local changes in reactivity introduced by the reactor forcing functions. Over the course of the cycle the flux shape will, however, change as the isotopic composition changes. But at any point during the cycle the flux shape is invariable with respect to forcing function changes and is given by

$$
\frac{\mathrm{d} \phi}{\mathrm{dt}}=\frac{\rho(\mathrm{t})-\beta}{\wedge} \tilde{\phi}(\mathrm{t})+\sum_{\mathrm{j}=1}^{\mathrm{n}_{\mathrm{p}}} \lambda_{\mathrm{fj}} \tilde{\mathrm{C}}_{\mathrm{j}}(\mathrm{t})+\tilde{\mathrm{Q}}(\mathrm{t})
$$

and

$$
\frac{\mathrm{d} \tilde{\mathrm{C}}_{\mathrm{i}}}{\mathrm{dt}}=\frac{\beta_{\mathrm{fi}} \tilde{\phi}(\mathrm{t})}{\wedge}-\lambda_{\mathrm{fi}} \tilde{\mathrm{C}}_{\mathrm{i}}(\mathrm{t}) \quad \mathrm{i}=1, \ldots, \mathrm{n}_{\mathrm{p}}
$$

where

$$
\begin{array}{ll}
\tilde{\phi}(\mathrm{t}) & =\text { fission power, } \\
\rho(\mathrm{t}) & =\text { reactivity, } \\
\wedge & =\text { neutron lifetime, } \\
\tilde{\mathrm{C}}_{\mathrm{i}}(\mathrm{t}) & =\text { precursor concentration for the } \mathrm{i}^{\text {th }} \text { precursor group, } \\
\lambda_{\mathrm{fi}} & =\text { decay constant for the } \mathrm{i}^{\text {th }} \text { precursor group, }
\end{array}
$$




$$
\begin{array}{ll}
\tilde{\mathrm{Q}}(\mathrm{t}) & =\text { production rate of external source, } \\
\beta_{\mathrm{fi}} & =\text { effective delayed-neutron fraction for the } \mathrm{i}^{\mathrm{th}} \text { precursor group, and } \\
\beta & =\text { effective delayed-neutron fraction. }
\end{array}
$$

The amount of reactivity is always much less than $\beta$ and the rate of reactivity addition is small so that $\frac{\mathrm{d} \phi}{\mathrm{dt}}$ is almost zero and can be set to zero without affecting the accuracy of the solution. The above equations then become

$$
0=[\rho(t)-1] \tilde{\phi}(t)+\frac{\Lambda}{\beta}\left[\sum_{j=1}^{n_{p}} \lambda_{f j} \tilde{\mathrm{C}}_{j}(t)+\tilde{Q}(t)\right]
$$

and

$$
\frac{\wedge}{\beta} \frac{\mathrm{d} \tilde{\mathrm{C}}_{1}}{\mathrm{dt}}=\mathrm{a}_{1} \tilde{\phi}(\mathrm{t})-\frac{\wedge}{\beta} \lambda_{\mathrm{fi}} \tilde{\mathrm{C}}_{1}(\mathrm{t})
$$

where

$$
a_{1}=\frac{\beta_{\mathrm{fi}_{1}}}{\beta}
$$

and $\rho(\mathrm{t})$ now has units of dollars.

The parameter $\frac{\Lambda}{\beta}$ in the above equations can be eliminated by nondimensionalizing the fission power, precursor concentration and the production rate of the external source. At the steady-state initial condition

$$
0=-\tilde{\phi}(0)+\frac{\Lambda}{\beta}\left[\sum_{\mathrm{J}=1}^{\mathrm{n}_{\mathrm{p}}} \lambda_{\mathrm{fj}} \tilde{\mathrm{C}}_{\mathrm{j}}(0)+\tilde{\mathrm{Q}}(0)\right]
$$


and

$$
0=\mathrm{a}_{\mathrm{i}} \tilde{\phi}(0)-\frac{\wedge}{\beta} \lambda_{\mathrm{fi}} \tilde{\mathrm{C}}_{1}(0)
$$

Combining these two equations gives

$$
0=a_{\mathrm{i}}\left[\sum_{\mathrm{J}=1}^{\mathrm{n}_{\mathrm{p}}} \lambda_{\mathrm{ff}} \tilde{\mathrm{C}}_{\mathrm{J}}(0)+\tilde{\mathrm{Q}}(0)\right]-\lambda_{\mathrm{fi}} \tilde{\mathrm{C}}_{\mathrm{i}}(0)
$$

while Eq. (7) gives

$$
\frac{\wedge}{\beta}=\frac{\mathrm{a}_{1} \tilde{\phi}(0)}{\lambda_{\mathrm{fi}} \tilde{\mathrm{C}}_{1}(0)}
$$

Substituting Eq. (9) into Eq. (3) gives

$$
0=[\rho(t)-1] \tilde{\phi}(\mathrm{t})+\frac{\mathrm{a}_{1} \tilde{\phi}(0)}{\lambda_{\mathrm{fi}} \tilde{\mathrm{C}}_{\mathrm{l}}(0)}\left[\sum_{\mathrm{J}=1}^{\mathrm{n}_{\mathrm{p}}} \lambda_{\mathrm{fj}} \tilde{\mathrm{C}}_{\mathrm{J}}(\mathrm{t})+\tilde{\mathrm{Q}}(\mathrm{t})\right]
$$

and Eq. (9) into Eq. (4) gives

$$
\frac{\mathrm{d} \tilde{\mathrm{C}}_{1}}{\mathrm{dt}}=\lambda_{\mathrm{fi}} \tilde{\mathrm{C}}_{1}(0) \frac{\tilde{\phi}(\mathrm{t})}{\tilde{\phi}(0)}-\lambda_{\mathrm{fi}} \tilde{\mathrm{C}}_{1}(\mathrm{t})
$$


Defining the nondimensional variables

$$
\phi(t)=\frac{\tilde{\phi}(\mathrm{t})}{\tilde{\phi}(0)}, \mathrm{C}_{\mathrm{i}}(\mathrm{t})=\frac{\tilde{\mathrm{C}}_{\mathrm{i}}(\mathrm{t})}{\tilde{\mathrm{C}}_{\mathrm{i}}(0)} \text { and } \mathrm{Q}(\mathrm{t})=\frac{\tilde{\mathrm{Q}}(\mathrm{t})}{\tilde{\mathrm{Q}}(0)} \text {, }
$$

the above two equations become

$$
0=[\rho(t)-1] \phi(t)+\frac{a_{i}}{\lambda_{f i} \tilde{C}_{i}(0)}\left[\sum_{j=1}^{n_{p}} \lambda_{f j} C_{j}(t) \tilde{C}_{j}(0)+Q(t) \tilde{Q}(0)\right]
$$

and

$$
\frac{d C_{i}}{d t}=\lambda_{f i} \phi(t)-\lambda_{f i} C_{i}(t)
$$

where $\tilde{\mathrm{C}}_{\mathrm{i}}(0)$ is obtained by solving Eq. (8).

In Sect. $\mathrm{V}$ we use a simplified version of the above equations. Let the external source strength be zero and let the number of precursor groups be one. The Eqs. (13) and (14) become

$$
0=[\rho(t)-1] \phi(t)+C(t)
$$

and

$$
\frac{\mathrm{dC}}{\mathrm{dt}}=\lambda_{\mathrm{f}} \phi(\mathrm{t})-\lambda_{\mathrm{f}} \mathrm{C}(\mathrm{t})
$$

Differentiating Eq. (15) and substituting the result and Eq. (15) into Eq. (16) gives

$$
[\rho(\mathrm{t})-1] \frac{\mathrm{d} \phi}{\mathrm{dt}}+\left[\lambda_{\mathrm{f}} \rho(\mathrm{t})+\frac{\mathrm{d} \rho}{\mathrm{dt}}\right] \phi(\mathrm{t})=0 .
$$


The fission power normalized to the initial total power (decay plus fission) is given by

$$
\mathrm{P}_{\mathrm{f}}(\mathrm{t})=\frac{\phi(\mathrm{t}) \tilde{\phi}(0)}{\mathrm{P}_{\mathrm{T}}(0)}
$$

\section{B. Delayed Feedbacks}

Through the combined use of metal fuel, sodium coolant and careful arrangement of the reactor materials, a set of reactivity feedbacks can be realized that ensures power will inherently adjust to a level that is safe for the inlet temperature and flowrate presented to the reactor by the heat sink. The large reactivity vested in the coolant temperature rise compared to the fuel temperature rise results in the reactor inherently adjusting power to a level that is safe. Too much power raises the coolant temperature which in turn causes the power to drop. The size of the effect is what differentiates the IFR from other reactors; a relatively small change in coolant temperature can be used to compensate a relatively large change in power. This selfregulating process is exploited in the design process to limit temperatures during accidents.

Given that the reactivity feedbacks largely determine accident response, it is important that they be well-characterized. Part of this involves determining what one can hope to resolve in the reactor response. The first step is to examine the time constant associated with each reactivity feedback and determine its role in the reactor response. Typical values for time constants are shown in Table I. The time rate of change of the reactor forcing functions for the five classes of unprotected accidents are such that only the control rod driveline and vessel wall temperatures behave nonquasistatically with respect to the temperature fields driving them. These feedbacks are, on the other hand, small compared to the net coolant feedback. We will ignore these delays, treat these two feedbacks as being in quasistatic equilibrium with the instantaneous power, flowrate and inlet temperature and accept the associated error in the transient response. The methodology of Sect. IV allows a measure of this error be included in the identified model so that its effect on accident prediction is represented. 
TABLE I. Typical Time Constants for a Metal Fueled Liquid Metal Reactor

\begin{tabular}{llc}
\hline \multicolumn{1}{c}{ Reactivity Feedback } & Process Variable & Time Constant (s) \\
\hline Doppler and axial expansion & Fuel pellet temperature & 0.2 \\
Sodium density & Coolant transport & 0.2 \\
Radial expansion & Load pad temperature & \\
& $\quad$ ACLP & 0.2 \\
& TLP & 0.9 \\
Control rod & Control rod driveline & 32 \\
& temperature & \\
Gridplate & Gridplate temperature & 200 \\
\hline
\end{tabular}

The assumption that each feedback component is in quasistatic equilibrium with the temperature field forcing it leads to an expression for reactivity where the number of parameters equals the number of reactor forcing functions. The expression, given by Eq. (27), is derived by writing the net change in reactivity

$$
\begin{aligned}
\delta \rho & =\alpha_{\mathrm{g}} \delta \mathrm{T}_{\mathrm{i}}+\alpha_{\mathrm{b}} \delta \Delta \mathrm{T}_{\mathrm{c}}+\alpha_{\mathrm{cr}} \delta \mathrm{T}_{\text {out }}+\alpha_{\mathrm{v}} \delta \mathrm{T}_{\mathrm{i}} \\
& +\sum_{\mathrm{k}} \int_{\mathrm{V}_{\mathrm{k}}} \mathrm{dV} \alpha_{\mathrm{Na}}(\mathrm{r}) \delta \mathrm{T}_{\mathrm{c}}(\mathrm{r})+\sum_{\mathrm{k}} \int_{\mathrm{V}_{\mathrm{k}}} \mathrm{dV} \alpha_{\mathrm{d}}(\underline{\mathrm{r}}) \delta \mathrm{T}_{\mathrm{f}}(\mathrm{r}) \\
& +\sum_{\mathrm{k}} \alpha_{\mathrm{ck}} \delta \overline{\mathrm{T}}_{\mathrm{fk}}
\end{aligned}
$$

where

$\mathrm{T}_{\mathrm{i}} \quad=$ reactor inlet temperature,

$\Delta \mathrm{T}_{\mathrm{c}} \quad=$ reactor coolant temperature rise,

$\mathrm{T}_{\text {out }}=$ reactor coolant outlet temperature,

$T_{c}(\underline{r})=$ coolant temperature at some location in the reactor,

$\mathrm{T}_{\mathrm{f}}(\underline{\mathrm{r}})=$ fuel temperature at some location in the reactor,

$\overline{\mathrm{T}}_{\mathrm{f}} \quad=$ axial average of fuel temperature, and

$\alpha=$ feedback coefficient, 
and where the subscripts on the feedback coefficients represent gridplate, bowing, control rod, vessel, coolant density, Doppler and fuel axial expansion feedback, respectively. The subscript $\mathrm{k}$ denotes coolant channel number. Now introduce the approximation

$$
\int_{\mathrm{V}_{\mathrm{k}}} \mathrm{dV} \alpha_{\mathrm{j}}(\mathrm{r}) \delta \mathrm{T}_{\mathrm{j}}(\mathrm{r}) \approx \bar{\alpha}_{\mathrm{jk}} \int_{\mathrm{V}_{\mathrm{k}}} \mathrm{dV} \delta \mathrm{T}_{\mathrm{j}}(\mathrm{r}), \mathrm{j}=\mathrm{d} \text { or } \mathrm{Na}
$$

where

$$
\bar{\alpha}_{j k}=\frac{\int_{V_{k}} d V \alpha_{j}(r)}{\int_{V_{k}} d V}
$$

and note that the spatial shape of the power and flow distributions are very nearly independent of time and that the power is very nearly axially symmetric about the core midplane. This leads to the following expressions for quantities appearing in Eq. (18),

$$
\begin{aligned}
& \delta \Delta \mathrm{T}_{\mathrm{c}}=\Delta \mathrm{T}_{\mathrm{c} 100} \delta\left(\frac{\mathrm{P}_{\mathrm{T}}}{\mathrm{W}}\right), \\
& \delta \mathrm{T}_{\text {out }}=\delta \mathrm{T}_{\mathrm{i}}+\Delta \mathrm{T}_{\mathrm{c} 100} \delta\left(\frac{\mathrm{P}_{\mathrm{T}}}{\mathrm{W}}\right), \\
& \int_{\mathrm{V}_{\mathrm{k}}} \mathrm{dV} \delta \mathrm{T}_{\mathrm{c}}(\mathrm{r})=\mathrm{V}_{\mathrm{k}}\left\{\delta \mathrm{T}_{\mathrm{i}}+\frac{\Delta \mathrm{T}_{\mathrm{cl00}}}{2} \delta\left(\frac{\mathrm{P}_{\mathrm{T}}}{\mathrm{W}}\right)\right\},
\end{aligned}
$$




$$
\begin{aligned}
& \int_{\mathrm{V}_{\mathrm{k}}} \mathrm{dV} \delta \mathrm{T}_{\mathrm{f}}(\underline{\mathrm{r}})=\mathrm{V}_{\mathrm{k}}\left\{\delta \mathrm{T}_{\mathrm{i}}+\frac{\Delta \mathrm{T}_{\mathrm{ck} 100}}{2} \delta\left[\frac{\mathrm{P}_{\mathrm{T}}}{\mathrm{W}}\right]+\frac{\Delta \mathrm{T}_{\mathrm{fk} 100}}{2} \delta \mathrm{P}_{\mathrm{T}}\right\}, \\
& \delta \overline{\mathrm{T}}_{\mathrm{fk}}=\delta \mathrm{T}_{\mathrm{i}}+\frac{\Delta \mathrm{T}_{\mathrm{ck} 100}}{2} \delta\left[\frac{\mathrm{P}_{\mathrm{T}}}{\mathrm{W}}\right]+\frac{\Delta \mathrm{T}_{\text {fk100 }}}{2} \delta \mathrm{P}_{\mathrm{T}} \text {, and }
\end{aligned}
$$

where

$$
\begin{array}{ll}
\mathrm{P}_{\mathrm{T}} & =\text { fission plus decay power normalized to reference condition, } \\
\mathrm{W} & =\text { flowrate normalized to reference condition, } \\
\Delta \mathrm{T}_{\mathrm{ck} 100} & =\text { average coolant temperature rise at reference condition, and } \\
\Delta \mathrm{T}_{\mathrm{fk} 100} & =\text { average fuel temperature rise at reference condition. }
\end{array}
$$

Substituting the above expressions into Eq. (18) gives

$$
\delta \rho=\mathrm{A} \delta \mathrm{P}_{\mathrm{T}}+\mathrm{B} \delta\left[\frac{\mathrm{P}_{\mathrm{T}}}{\mathrm{W}}\right]+\mathrm{C} \delta \mathrm{T}_{\mathrm{i}}+\frac{\mathrm{d} \rho_{\mathrm{rod}}}{\mathrm{dx}} \delta \mathrm{x}
$$

where $\mathrm{A}, \mathrm{B}$, and $\mathrm{C}$ are constants. If the feedback components in Eq. (18) are linear, then integration of the above equation gives the change in reactivity relative to the reference condition sought,

$$
\rho=\mathrm{A}\left(\mathrm{P}_{\mathrm{T}}-1\right)+\mathrm{B}\left[\frac{\mathrm{P}_{\mathrm{T}}}{\mathrm{W}}-1\right)+\mathrm{C} \delta \mathrm{T}_{\mathrm{i}}+\int \frac{\mathrm{d} \rho_{\mathrm{ROD}}}{\mathrm{dx}} \mathrm{dx}
$$

With the exception of the Doppler and bowing, the feedbacks are linear. While the Doppler coefficient does change with fuel temperature, the fuel temperature change in a metal fueled LMR is small enough that this nonlinearity can be ignored. 


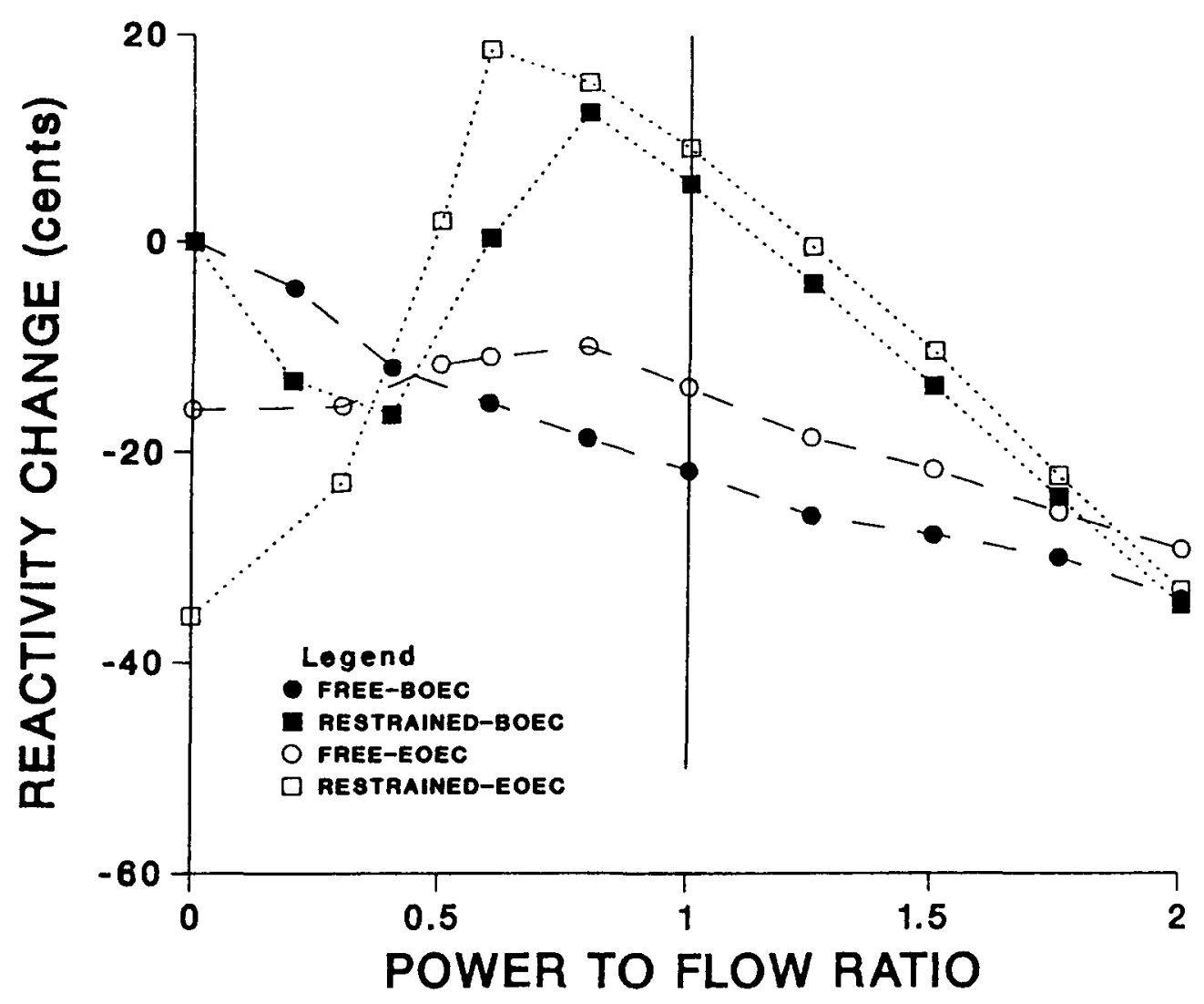

Fig. 1. Bowing Reactivity as a Function of Power-to-flow Ratio

The typical behavior of bowing reactivity as a function of the power-to-flow ratio is shown in Fig. 1.[5] Note that the greatest reactivity occurs at a power-to-flow ratio much less than unity. In general the designer will strive to achieve this over the cycle and over all core loadings in order to obtain favorable passive safety response characteristics. (In EBR-II, one does not always observe this trend but then the EBR-II core was not designed with passive safety in mind). Thus, providing $\mathrm{A}, \mathrm{B}$, and $\mathrm{C}$ are measured locally at full power conditions, then the prediction of bowing reactivity for power-to-flow ratios terminating at greater than unity will be best estimate. Predictions for less than unity may overestimate (but never underestimate) the positive bowing reactivity and hence cause the power to be overestimated. Thus, estimates of $\mathrm{A}, \mathrm{B}$, and $\mathrm{C}$ made at full power will not cause any positive reactivity associated with bowing to be underestimated. It should also be evident that the bowing nonlinearity will cause the value measured for A and B going from zero to full power at unity flow to differ from the value obtained locally at full power conditions. 


\section{Decay Heat}

The fission product nuclei that produce decay heat satisfy an analogous set of balance equations in space and time as the neutron precursors. Their concentrations are also separable functions in space and time so a set of point equations analogous to Eq. (2) for the delayedneutron precursors can be derived. The point equations for decay heat for group i are

$$
\frac{\mathrm{d} \psi_{1}}{\mathrm{dt}}=\beta_{\mathrm{d} 1} \mathrm{P}_{\mathrm{f}}(\mathrm{t})-\lambda_{\mathrm{d} 1} \psi_{1}(\mathrm{t}), \mathrm{i}=1, \ldots, \mathrm{n}_{\mathrm{d}}
$$

The total decay power normalized to the total initial power is the sum over all decay groups used

$$
P_{d}(t)=\sum_{i=1}^{n_{d}} \lambda_{d 1} \psi_{1}(t)
$$

The reactor response for the five accident classes that are to be predicted is fairly insensitive to variation in decay heat behavior across uranium and plutonium cores. After shutdown following infinite time full power operation, the decay heat from a U-235 fission differs by about $20 \%$ from that of a Pu-239 fission.[6] Reactor response will be affected by this difference only in the transient part following an accident. The long-term asymptotic state is determined by the total power according to Eq. (26) so that fission power for a given decay power will self-adjust to give zero reactivity. But during the transient the rate of change of fission power is slow enough that the decay power remains a second-order effect. Only after approaching the asymptotic state does decay power become a significant component of the thermal power. But at that time the reactor state is no longer affected by decay power as just described.

The insensitivity of the reactor response to the types of decay-heat-producing nuclei suggests that it may not be necessary to estimate the values of $\beta_{\mathrm{d} 1}$ and $\lambda_{\mathrm{d} 1} i=1, \ldots n_{\mathrm{d}}$. Rather, sufficiently accurate representation of decay heat influence is obtained by assuming nominal 
values for these parameters and then precomputing decay heat behavior from Eq. (29) and the fission power history. This computed decay power can then be supplied as input to the estimation step. That is, we will treat decay power as a forcing function when estimating parameter values, not as a quantity that itself needs to be estimated.

\section{PARAMETERS AND PERTURBATIONS}

The parameters to be estimated are the kinetics parameters $a_{i}, \lambda_{\mathrm{fi}} i=1, \ldots 6, \frac{\mathrm{d} \rho}{\mathrm{dx}}$ and the integral feedback parameters A, B, and C. The general idea is to selectively perturb the reactor so that the associated response is controlled by as few as possible of the parameters with as yet undetermined values. The principal consideration is that the response of the reactor be highly sensitive to these parameters. To the extent that this is true, the magnitude of the perturbation can be limited in the presence of a background of process and instrument noise. There are two cases to be considered. The greatest flexibility exists during startup when both zero power and full power tests can be conducted. Once into the cycle, zero power tests are no longer possible so modifications are needed to handle the midcycle case.

\section{A. Kinetics Parameters at Startup}

The reactor response at power levels below that at which temperature feedbacks are operating is controlled by the relative delayed-neutron fractions, the precursor decay constants, the control rod reactivity and the external source. This is seen in Eqs. (13) and (14).

The above parameters determine then the shape of the flux die-away to a dropped control rod in an initially critical core. By choosing an appropriate set of decay constants, the relative delayed-neutron fractions and the worth of the dropped rod can be obtained by fitting Eqs. (13) and (14) to the flux die-away. The rod can be dropped from an initial power great enough that the external source can be ignored. Alternatively, the source strength can be included for estimation. 
The differential rod worths are obtained from the reactivity associated with incremental step changes in rod position over the length of a rod. The reactivity for each position change is obtained from an inverse solution to the kinetics equations given by Eqs. (13) and (14). The values for the relative delayed-neutron fractions and the precursor decay constants are taken from the rod drop experiment.

\section{B. Integral Feedback Parameters at Startup}

The integral feedback parameters $\mathrm{A}, \mathrm{B}$, and $\mathrm{C}$ control reactor response to changes in the reactor forcing functions when temperature feedbacks are operating. If the forcing functions are changed quasistatically, net reactivity remains zero and from Eq. (27) these three parameters, along with rod worth which is already known, alone control the reactor response. The value of $\mathrm{B} / \mathrm{A}$ is determined by changing reactor flowrate and fitting Eq. (27) to the reactor response. The value of $\mathrm{A}$ is determined next by changing rod position. Then $\mathrm{C} / \mathrm{A}$ is determined by changing inlet temperature. These parameter values should be determined at full power to ensure that we are located on a point of Fig. 1 where the slope is negative as already discussed.

The sequence of perturbations performed at startup is summarized in Table II.

\section{Modifications for Parameters at Midcycle}

The perturbation sequence just described is inappropriate for use at any time other than during startup. Once into the cycle, there is a rigid requirement that full power be maintained and so the zero power rod drop and rod motion perturbations of the previous subsection cannot be performed. Rod worths can, however, change by more than $10 \%$ over the cycle in a zero burnup swing core, so some means is needed to measure these at power in midcycle.

Part of the solution to obtaining rod worths at power in midcycle involves obtaining current values for the relative delayed-neutron fractions and precursor decay constants. These parameters are a function of the fuel isotopic composition and flux shape. However, the change 
TABLE II. Reactor Forcing Function Perturbations at Startup and Parameters Controlling Response

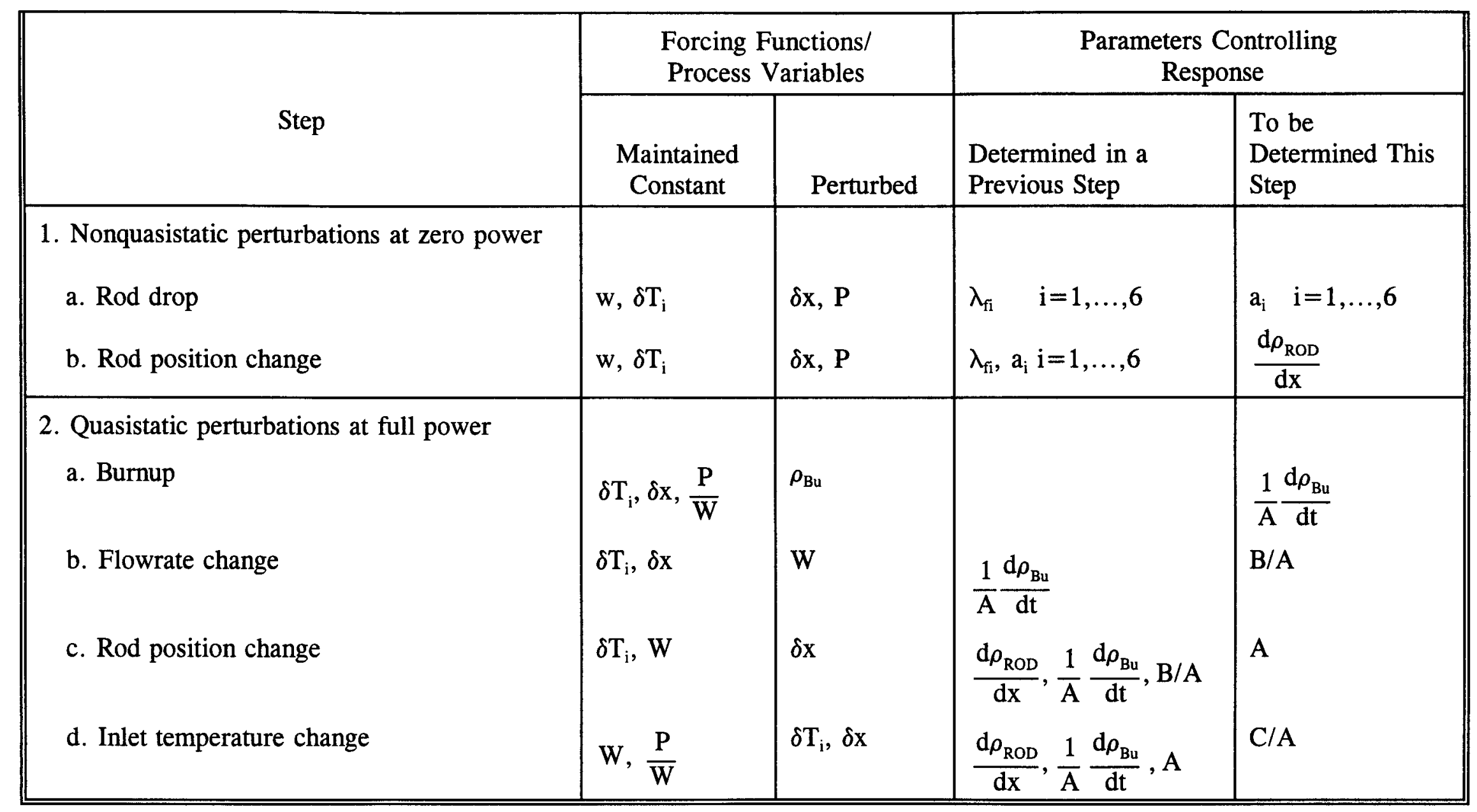


in these parameters due to burnup-induced changes in the flux and isotopics is small enough that they can be neglected. Only a fuel loading change can affect the fractions and decay constants in a nonnegligible way. If this is so, these parameters need only be measured during startup after a loading change, as per the previous subsection, and assume that the values remain unchanged until the next loading.

With the values of the relative delayed-neutron fractions and decay constants known, rod worths can be measured at power. The first step is to measure $\frac{1}{\mathrm{~A}} \frac{\mathrm{d} \rho}{\mathrm{dx}}$ by introducing slow changes in rod position so that the left side of Eq. (27) remains zero. By moving paired rods in opposite directions, small increments at a time, this quantity can be obtained over the length of each rod with minimal perturbation to reactor power. The values of $B / A$ and $C / A$ can be obtained in the same way as during startup.

The second step is to measure the only remaining unknown parameter, A. To do so, integrate Eq. (14)

$$
C_{i}(t)=\lambda_{f i} e^{-\lambda_{n} t} \int_{-\infty}^{t} \phi\left(t^{\prime}\right) e^{\lambda_{a^{\prime}}{ }^{\prime}} d t^{\prime}, \quad i=1, \ldots n_{p}
$$

and substitute the result into Eq. (13) to get

$$
\phi(t)[1-\rho(t)]=\frac{a_{i}}{\lambda_{f i} \tilde{C}_{i}(0)}\left[\sum_{i=1}^{n_{p}} \lambda_{f i}^{2} \tilde{C}_{i}(0) e^{-\lambda_{n} t^{t}} \int_{0}^{t} \phi\left(t^{\prime}\right) e^{\lambda_{n} t^{\prime}} d t^{\prime}+Q(t) \tilde{Q}(0)\right] .
$$

The above equation is solved for $\rho$ for given forcing functions. This result is substituted into Eq. (27) and the parameter A solved for.

The forcing functions used to determine A above should satisfy three criteria. The reactor inlet and outlet temperatures should be maintained constant so that the longer feedback 
time constants (shield and reflector assemblies, control rod driveline and vessel wall) are not excited since it was assumed in Eq. (27) that these feedbacks remained in quasistatic equilibrium. The rate at which the forcing functions are changed should be slow enough that the remaining reactivity feedbacks (fuel pin, coolant transport and fueled assembly hexcan) in Eq. (27) remain in quasistatic equilibrium. Finally, the rate of change should, however, be fast enough that at least some of the precursors are excited so that $\rho(t)$ is not zero.

The entire sequence of perturbations to be performed at midcycle while at power is summarized in Table III.

\section{IDENTIFICATION OF THE REACTOR SYSTEM}

This section is concerned with the development of a method for using plant data to improve the prediction of the accident behavior of the reactor. Time-dependent models have long been used to predict the dynamic behavior of components in nuclear plants. However, through the use of discrete system filtering theory, on-line measurements can be used to improve upon the quality of such models. The technique provides a systematic means for adjusting unknown or uncertain parameters of a simulation to force agreement between the model and the actual plant dynamics.

The technique makes use of information contained in both the equations of the system dynamics and measurements made on the plant. A Kalman filter is used to process this information to obtain an optimal estimate for the reactor state vector. Then using a result that appears to be not well-known, the state vector estimate is used to calculate the likelihood function, the metric we take for how well the plant and model agree. A search over model parameter values to maximize this metric yields the set of parameter values that most likely

produced the measured data. A final hypothesis test is performed to check that the identified model is consistent with the original measured data. 
TABLE III. Reactor Forcing Function Perturbations at Midcycle and Parameters Controlling Response

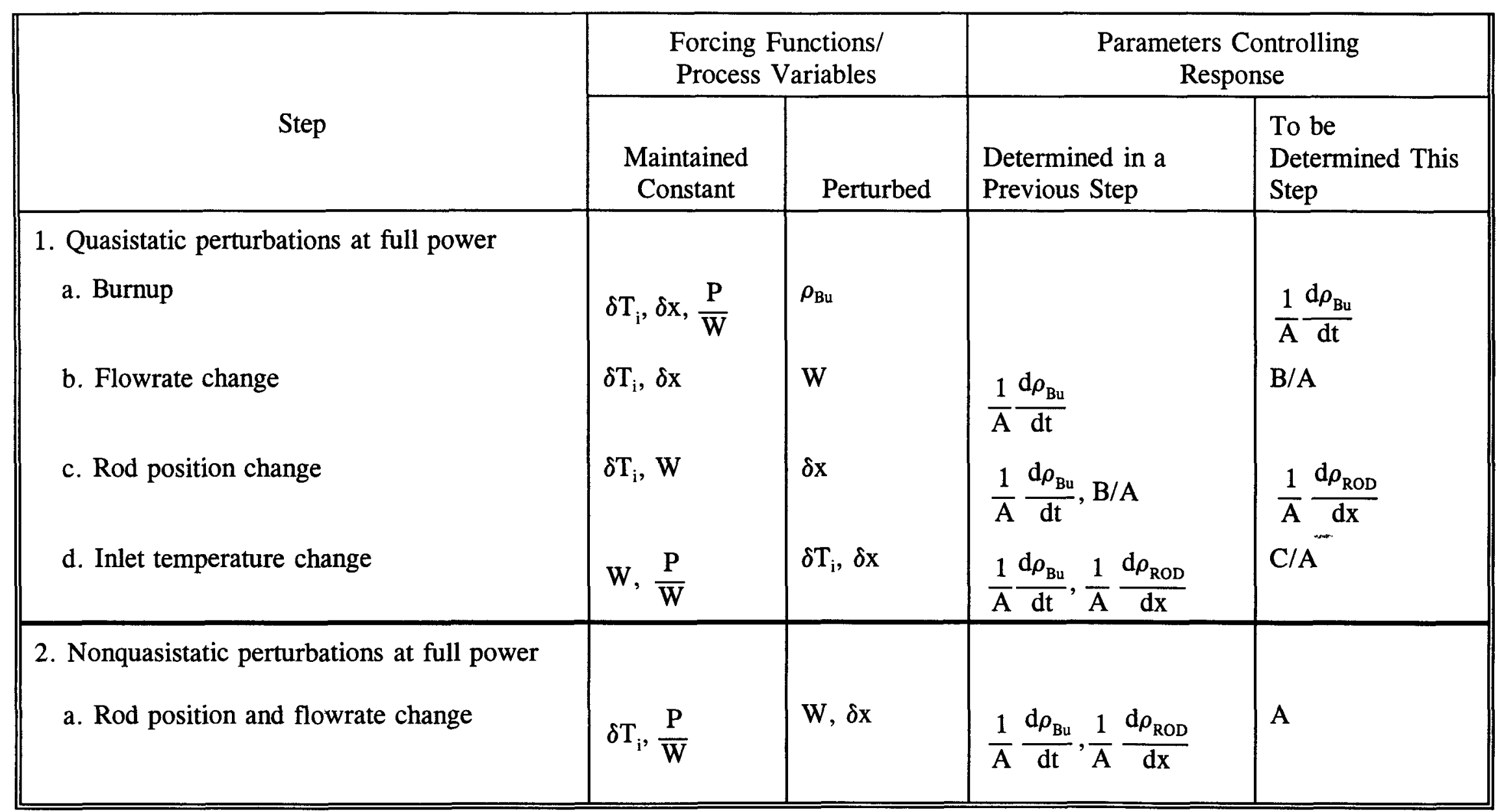




\section{A. Nonlinear Probabilistic Simulation Model}

The state of the reactor can be described by a set of nonlinear differential equations

$$
\frac{\mathrm{d}}{\mathrm{dt}} \underline{\mathrm{x}}(\mathrm{t})=\underline{\mathrm{f}}_{\mathrm{c}}[\underline{\mathrm{x}}(\mathrm{t}), \underline{\mathrm{u}}(\mathrm{t})]
$$

and

$$
\underline{y}(t)=g[\underline{x}(t), \underline{u}(t)]
$$

where

$$
\begin{aligned}
& x(t)=n \times 1 \text { state vector, } \\
& u(t)=r \times 1 \text { input vector, and } \\
& y(t)=m \times 1 \text { output vector. }
\end{aligned}
$$

This set of equations is derived from first principles knowledge of the reactor operation. The specific equations used in this work are given in Sect. II.

Errors in the system equations and in the measurement process are idealized as zero mean random white sequences. This assumption is a restriction of the Kalman filter, which is only formulated for this case. The assumption results in a relatively simple set of equations for the Kalman filter. To incorporate modeling and measurement error into the above equations, first assume $\underline{u}$ can change value only at times $t_{k}(k=0,1, \ldots, n)$ and that $\underline{y}$ is sampled only at times $t_{k}$ and then solve the equations over the sample interval time step. Then insert random sequences to give

$$
\underline{\mathrm{x}}(\mathrm{k}+1)=\mathrm{f}_{\underline{\mathrm{d}}}\left[\underline{\mathrm{x}}(\mathrm{k}), \underline{\mathrm{u}}(\mathrm{k}), \underline{\alpha}(\mathrm{k}), \underline{\xi}_{\mathrm{u}}(\mathrm{k}), \underline{\xi}_{\alpha}(\mathrm{k})\right]+\underline{\xi}_{\mathrm{x}}(\mathrm{k})
$$

and

$$
\mathrm{y}(\mathrm{k})=\mathrm{g}\left[\underline{\mathrm{x}}(\mathrm{k}), \underline{\mathrm{u}}(\mathrm{k}), \underline{\alpha}(\mathrm{k}), \underline{\xi}_{\mathrm{u}}(\mathrm{k}), \underline{\xi}_{\alpha}(\mathrm{k})\right]+\underline{\eta}(\mathrm{k})
$$


where the deterministic part of the input and parameter vectors are represented by $\underline{u}(\mathrm{k})$ and $\underline{\alpha}(\mathrm{k})$ and the uncertain part by $\xi_{\mathrm{u}}(\mathrm{k})$ and $\underline{\xi}_{\alpha}(\mathrm{k})$. The parameter vector need not appear explicitly since its elements can be regarded as inputs. Errors in the state equation are represented by the random sequence $\xi_{x}(k)$. Noise in the plant measurements are modeled by a random sequence $\eta(\mathrm{k})$ in the measurement equation. The random sequences are assumed zero mean Gaussian and white. The variance of the random sequences are given by

$$
\begin{aligned}
& \operatorname{Var}\left[\xi_{u}(k)\right]=Q_{u}(k), \quad \operatorname{Var}\left[\xi_{x}(k)\right]=Q_{x}(k), \\
& \operatorname{Var}[\eta(k)]=R(k), \text { and } \\
& \operatorname{E}\left[\xi_{u}(k) \eta(q)^{T}\right]=0 .
\end{aligned}
$$

for all $\mathrm{k}$ and $\mathrm{q}$.

The assumption that model error and measurement noise are zero mean white Gaussian sequences has great precedence in the literature, in part because it renders linear systems filtering theory mathematically tractable. While an idealization, there is some phenomenological basis to the assumptions. Measurement noise exhibits these properties[7] and modeling errors that result from treating fast processes as quasistatic tend to be random.[8]

\section{B. Parameter Estimation by Maximizing the Likelihood Function}

The parameters in the model structure are to be adjusted so that the model and measured data are forced to agree. The metric measuring the degree of agreement is appropriately probabilistic since the model is stochastic. The approach is to adjust model parameters so that the probability that the model generated the data is maximized. This is the classical likelihood method and it requires that the likelihood function for Eq. (33) be calculated.

The method for calculating the likelihood function is based on the suggestion of Schweppe.[10] He first showed that the likelihood function for the linear case could be written 
as an expression containing the covariance matrix for the state update estimate error appearing in the Kalman filter algorithm.[9] For the nonlinear case, Schweppe suggested that the likelihood function for $\mathrm{Eq}$. (33) could be obtained by linearizing the equation and using the extended Kalman filter algorithm to provide the covariance error matrix. We have followed this approach and the details are given in Appendix A. Given the measured data $\delta y(1), \ldots, \delta y(n)$ when the model is driven by the input sequence $\delta \underline{u}(1), \ldots, \delta \underline{u}(n)$, the likelihood function for Eq. (33) is

$$
\begin{aligned}
& \ln \mathrm{f}[\mathrm{y}(1), \ldots, \mathrm{y}(\mathrm{n})] \\
& =-\frac{1}{2} \sum_{\mathrm{k}=1}^{\mathrm{n}}\left[\underline{\mathrm{r}}(\mathrm{k})^{\mathrm{r}} \sum(\mathrm{k} \mid \mathrm{k}-1)^{-1} \underline{\mathrm{r}}(\mathrm{k})+\mathrm{r} \ln 2 \pi+\ln \left|\operatorname{det} \sum(\mathrm{k} \mid \mathrm{k}-1)\right|\right]
\end{aligned}
$$

where

$$
\underline{\mathrm{r}}(\mathrm{k})=\underline{\mathrm{y}}(\mathrm{k})-\mathrm{g}[\underline{\hat{\mathbf{x}}}(\mathrm{k} \mid \mathrm{k}-1), \underline{\mathrm{u}}(\mathrm{k}), 0] \text {. }
$$

where $\Sigma(\mathrm{k} \mid \mathrm{k}-1)$ is the measurement residual covariance matrix obtained from the extended Kalman filter algorithm.

The parameter values that improve agreement between model and measured data satisfy

$$
\max _{\underline{\alpha}} \ln \mathrm{f}[\mathrm{y}(1), \ldots, \mathrm{y}(\mathrm{n}) \mid \underline{\alpha}]
$$

\section{Predictions Using the Probabilistic Model}

The purpose for identifying the reactor system is to make predictions of how the reactor will respond during unprotected upsets so that a comparison with safety limits can be made. In general the process variable of interest is written as a measurement equation but with zero measurement noise since the underlying value is of interest, not the sensor noise corrupted value, 


$$
\underline{\mathrm{z}}(\mathrm{k})=\mathrm{g}\left[\underline{\mathrm{x}}(\mathrm{k}), \underline{\mathrm{u}}(\mathrm{k}), \underline{\xi}_{\mathrm{u}}(\mathrm{k})\right]
$$

where $\underline{z}(k)$ is the process variable. Because $\underline{z}(k)$ is a stochastic variable it has a cumulative distribution function (cdf). The goal is to find the cdf so that the probability that a process variable is within safety limits can be stated.

To find the cdf of $\underline{z}(\mathrm{k})$, the first step is to determine the statistical properties implied by the first line of Eq. (33). To do so we run the extended Kalman filter with the output measurement noise variance matrix, $R(k)$, set to infinity. The $\underline{\hat{x}}(k \mid k)=\underline{\hat{x}}(k \mid k-1)$ and the state estimate $\hat{\mathbf{x}}(\mathrm{k} \mid \mathrm{k}-1)$ is given by

$$
\hat{\mathrm{x}}(\mathrm{k} \mid \mathrm{k}-1)=\underline{\mathrm{f}}[\mathbf{\mathrm { x }}(\mathrm{k}-1 \mid \mathrm{k}-2), \underline{\mathrm{u}}(\mathrm{k}-1), 0]
$$

which does not depend on the output measurements $y_{m}(1), \ldots, y_{m}(N)$. We still have, however,

$$
\underline{\mathbf{x}}(\mathrm{k})-\underline{\hat{x}}(\mathrm{k} \mid \mathrm{k}-1) \sim \mathrm{N}[0, \mathrm{P}(\mathrm{k} \mid \mathrm{k}-1)] .
$$

The second step is to use the above property to determine the statistical properties of $\underline{\underline{z}}(\mathbf{k})$ in Eq. (37). To do so, note that by previous definitions

$$
\underline{\mathrm{r}}(\mathrm{k})=\underline{\mathrm{y}}(\mathrm{k})-\hat{\mathrm{l}}(\mathrm{k} \mid \mathrm{k}-1)
$$

and

$$
\hat{l}(\mathrm{k} \mid \mathrm{k}-1)=\mathrm{g}[\hat{\underline{\imath}}(\mathrm{k} \mid \mathrm{k}-1)], \underline{\mathrm{u}}(\mathrm{k}), 0] .
$$

But from Eq. (A12)

$$
\underline{\mathrm{r}}(\mathrm{k})=\mathrm{C}(\mathrm{k})[\underline{\mathrm{x}}(\mathrm{k})-\underline{\hat{\mathrm{\gamma}}}(\mathrm{k} \mid \mathrm{k}-1)]+\mathrm{E}(\mathrm{k}) \underline{\xi}_{\mathrm{u}}(\mathrm{k})+\underline{\eta}(\mathrm{k}) .
$$


If we assume no output measurement noise, which is the case of interest and is given by Eq. (37) then

$$
\underline{\mathbf{r}}(\mathrm{k})=\mathrm{C}(\mathrm{k})[\underline{\mathrm{x}}(\mathrm{k})-\hat{\mathrm{x}}(\mathrm{k} \mid \mathrm{k}-1)]+\mathrm{E}(\mathrm{k}) \underline{\xi}_{\mathrm{u}}(\mathrm{k}) .
$$

The above vector is a Gaussian with zero mean and variance

$$
\operatorname{Var}[\underline{r}(k)]=C(k) P(k \mid k-1) C(k)^{T}+E(k) Q_{u}(k) E(k)^{T}
$$

Then from Eq. (39)

$$
\underline{z}(\mathrm{k}) \sim \mathrm{N}[\underline{\mu}(\mathrm{k}), \Sigma(\mathrm{k} \mid \mathrm{k}-1)]
$$

where

$$
\underline{\mu}(\mathrm{k})=\hat{\underline{Y}}(\mathrm{k} \mid \mathrm{k}-1)
$$

and

$$
\Sigma(k \mid k-1)=C(k) P(k \mid k-1) C(k)^{T}+E(k) Q_{u}(k) E(k)^{T} .
$$

\section{Model Validation in Terms of Residuals}

Behind this method for predicting process variable values lie assumptions about noise properties and physics. We can check the validity of these assumptions and the estimated parameter values and model validity by looking at the properties of the measurement residuals. Let

$$
R(q)=\frac{1}{N-1} \sum_{k=1}^{N-1} \tilde{\underline{\mathbf{I}}}(k) \tilde{\underline{\tilde{r}}}(\mathrm{k}+q)^{n}
$$


where

$$
\underline{\tilde{\mathbf{r}}}(\mathrm{k})=\sum(\mathrm{k} \mid \mathrm{k}-1)^{-1 / 2} \underline{\mathrm{r}}(\mathrm{k})
$$

as suggested by Peterson[11] where $\underline{r}(\mathrm{k})$ is the measurement residual defined in Appendix A. The statistical properties of these matrices were not given by Peterson so they have been derived in Appendix B.

If the model is valid, then the actual plant response must be consistent with our statement of model accuracy. That is, the statistical properties of $R(q)$ implied by the model must be consistent with measured data. Specifically, compute the values of the elements of $R(q)$ from plant measurements $\mathrm{y}_{\mathrm{m}}(1), \ldots, \mathrm{y}_{\mathrm{m}}(\mathrm{N})$ using Eq. (43) to give

$$
\mathrm{R}(\mathrm{q})_{\mathrm{ij}}{ }^{*}=\text { value of } \mathrm{R}(\mathrm{q})_{\mathrm{ij}} \text { computed using plant measurements } \mathrm{y}_{\mathrm{m}}(1), \ldots, \mathrm{y}_{\mathrm{m}}(\mathrm{N}) \text {. }
$$

Now if Eq. (33) is a valid representation of the plant and if the errors introduced by the linearization are small, then $R(q)_{i j}{ }^{*}$ must be consistent with the statistical properties of $R(q)_{i j}$ given by Eq. (B9) in Appendix B. To be specific, if the identified model given by Eq. (33) is a valid representation of the measurements $y_{m}(1), \ldots, y_{m}(N)$, then for $f$ defined to be the fraction of $\mathbf{R}(q)^{*}$ elements for which

$$
\frac{\left|\mathrm{R}(\mathrm{q}) *_{\mathrm{ij}}-\mu_{\mathrm{R}\left(\mathrm{q}_{y}\right)}\right|}{\sigma_{\mathrm{R}\left(q_{y}\right.}}<3
$$

we must have $\mathrm{f}>0.995$.

\section{RESULTS}

The previous three sections constitute the basis for predicting unprotected reactor accident response. The physics of operation are represented in model parametric form by Eqs. (13), (14) 
and (27). Each of the perturbations listed in Tables II and III elicit a plant response that is sensitive to at most one of the as yet undetermined parameter values. The maximum likelihood method provides the means to extract the values of these parameters from the plant response and to quantify the parameter accuracy in such a way so as to be able to state the predictive accuracy of the model.

The focus in this section is on the assessment of the methodology. An assessment is made using simulated data and using actual reactor data. In both cases the assessment is made with respect to the EBR-II reactor operating with metal fuel. The EBR-II reactor is a prototype of the IFR. The present report describes the largely completed assessment using simulated data. The assessment at EBR-II is still in the early stages.

\section{A. $\quad \underline{\text { Simulation }}$}

The goal of the assessment was to determine if the reactor response to unprotected loss of flow and rod runout accidents as calculated from a reactor systems code can be predicted (i.e., bounded) from reactor response to perturbations at normal operation obtained from the same code. The issues are: to what degree can the stochastic approach successfully represent low-order model errors, and what are the size of these errors relative to the size that can be accommodated given the safety margins available? The SASSYS computer code model previously validated for EBR-II simulations[12] was used to calculate reactor response. To simulate process and instrument noise, noise having the properties shown in Table IV was added to the forcing function and response data. The perturbations used follow the outline given in Table II with two exceptions. The parameter C/A was not estimated as reactor inlet temperature was held constant. Rod differential worth was not estimated, as rod reactivity was input directly to the simulation.

The relative delayed-neutron fractions were estimated from a simulated rod drop at steady-state critical and essentially zero power. The flux die-away for the instantaneous insertion of -20 cents is shown in Fig. 2. The process for determining the fractions is described in detail 
TABLE IV. Properties of Noise Added to Simulation Data

\begin{tabular}{||l|l|c|c||}
\hline \multirow{2}{*}{ Noise } & \multicolumn{1}{|c|}{ Distribution } & \multicolumn{2}{c|}{ Properties } \\
\cline { 3 - 4 } & \multicolumn{1}{|c|}{$\mathrm{E}[\mathrm{x}]$} & $\mathrm{Var}[\mathrm{x}]^{1 / 2}$ \\
\hline \hline $\begin{array}{l}\text { Rod reactivity (as expressed } \\
\text { in terms of high worth rod } \\
\text { position) }\end{array}$ & $\begin{array}{l}\text { Gaussian and uncorrelated } \\
\text { in time }\end{array}$ & 0 & $0.015 \mathrm{in}$. \\
Reactor flowrate & See above & 0 & $0.5 \%$ \\
Power & See above & 0 & $0.2 \%$ \\
\hline
\end{tabular}

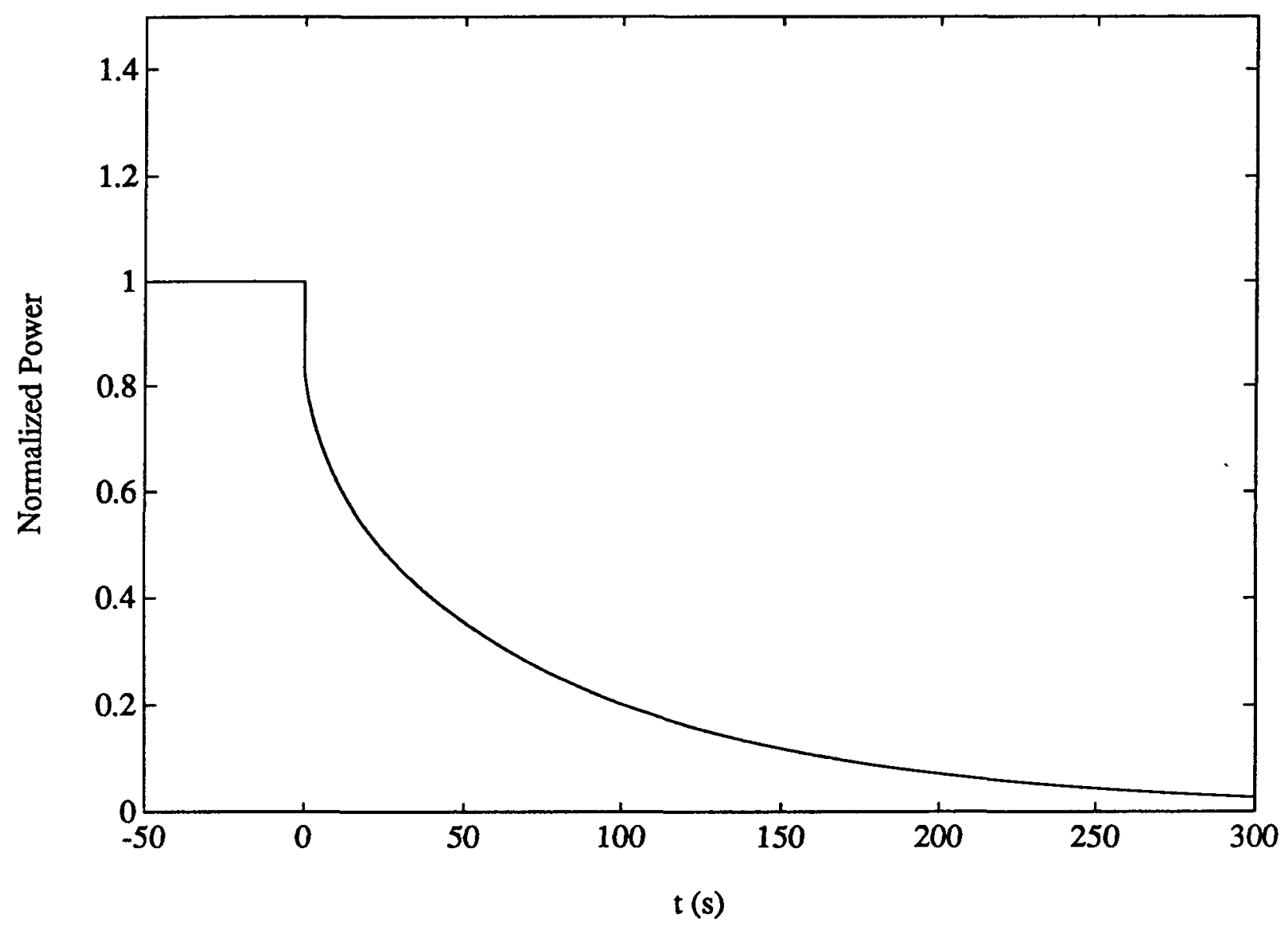

Fig. 2. Flux Die-away from Simulated Rod Drop of -20 Cents 
elsewhere.[13] Briefly, a set of six precursor groups and associated decay constants were assumed. Equation (14) was fit to the flux die-away to determine the unknown parameters: the reactivity insertion, the fractions and a term containing the external source strength. The estimated values for the fractions are compared in Table $\mathrm{V}$ with the values used in the simulation that produced the flux die-away. One sees that the estimates are very accurate.

TABLE V. Relative Delayed-neutron Fractions for a Simulated Rod Drop of -20 Cents

\begin{tabular}{|cc|c|c|}
\hline Input to Simulation & Estimated from Flux Die-away & Error, \% \\
\hline $\mathrm{a}^{1}$ & 0.0327 & 0.0326 & -0.31 \\
$\mathrm{a}_{2}$ & 0.1981 & 0.1985 & 0.20 \\
$\mathrm{a}_{3}$ & 0.1830 & 0.1835 & 0.27 \\
$\mathrm{a}_{4}$ & 0.4020 & 0.4026 & 0.15 \\
$\mathrm{a}_{5}$ & 0.1478 & 0.1471 & -0.47 \\
$\mathrm{a}_{6}$ & 0.0363 & 0.0355 & -2.25 \\
\hline
\end{tabular}

The above delayed-neutron fractions, however, are not inserted directly into the model. The computational load associated with determining the covariance matrix using the maximum likelihood is large and the potential for nonuniqueness of the solution exists. Rather than insert them directly, the six groups are collapsed into one group with an expected value and variance for one decay constant according to the procedure described below. The consequence is a larger uncertainty in the dynamic component of the reactor response. However, only the loss of flow event exhibits an overshoot so the issue is whether the choice of a single precursor leads to an unacceptably large overshoot for this event.

Before proceeding to calculate the effective one group precursor, the integral feedback parameters in Table II must be determined. The value of B/A was obtained by changing reactor flowrate as shown in Fig. 3 and fitting Eq. (27) to the power response. The value of A was 
$-29-$
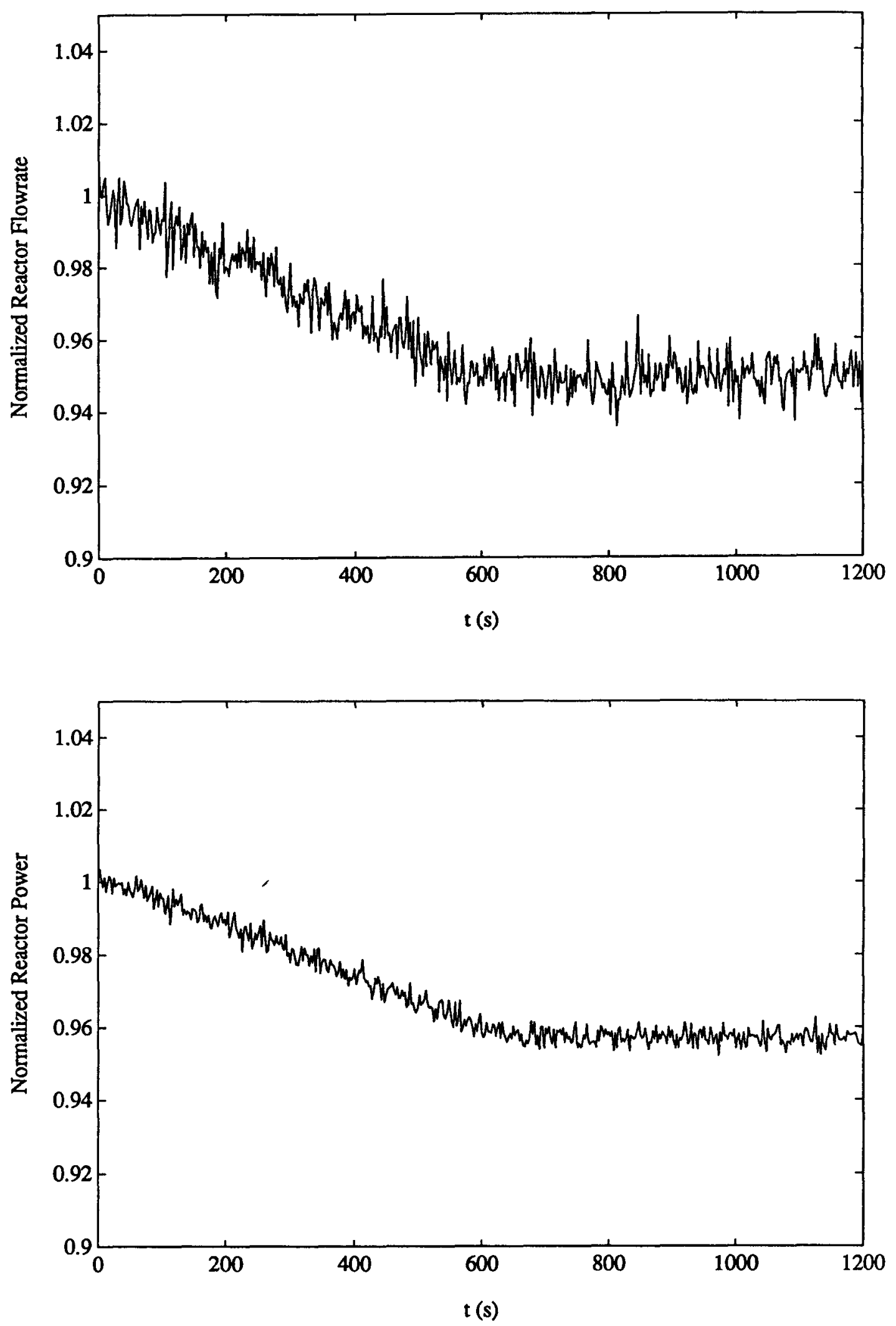

Fig. 3. Simulated Reactor Flowrate Perturbation 
then obtained by changing rod reactivity as shown in Fig. 4 and fitting Eq. (27) to the power response.

The procedure for calculating the effective one group precursor time constant takes into account the fact that a single group cannot represent the dynamic behavior of six groups. The only requirement, however, is that the peak overshoot in the loss of flow be well-predicted. The appropriate decay constant value then is the one that best fits the power response up to the overshoot as calculated using the six yield fractions from the rod drop. This power response is calculated using Eqs. (13), (14) and (27) and the measured values for the six group yield fractions and decay constants and the integral feedback parameters. The model to be fit to this response is Eq. (17) where the one group decay constant is a parameter.

The values of the expectation and variance of $\lambda, \mathrm{B} / \mathrm{A}, \mathrm{A}, \eta$ and the discrete form of Eqs. (17) and (27) constitute an identified model for predicting unprotected reactor response. Three-sigma uncertainty levels were calculated for an unprotected loss-of-flow event and a rod reactivity insertion event in EBR-II. The flowrate halving time for the loss-of-flow event is $14 \mathrm{~s}$ which leads to a peak power-to-flow ratio of 1.8 , about the same as that for a commercial- size LMR. The reactivity added in the rod withdrawal event is 16 cents inserted over $30 \mathrm{~s}$. This leads to a peak normalized power of 1.5, again typical of a commercial LMR. The three-sigma limit of the identified model should contain the response as calculated by SASSYS for the same forcing function.

The results are shown in Figs. 5 and 6. These figures compare the prediction of the identified model with the "actual" plant response. The dotted line shows the three-sigma confidence level predicted by the identified model; the solid line is the actual plant response, that is, the response calculated by SASSYS. The solid line falls within the dotted line as it should. 

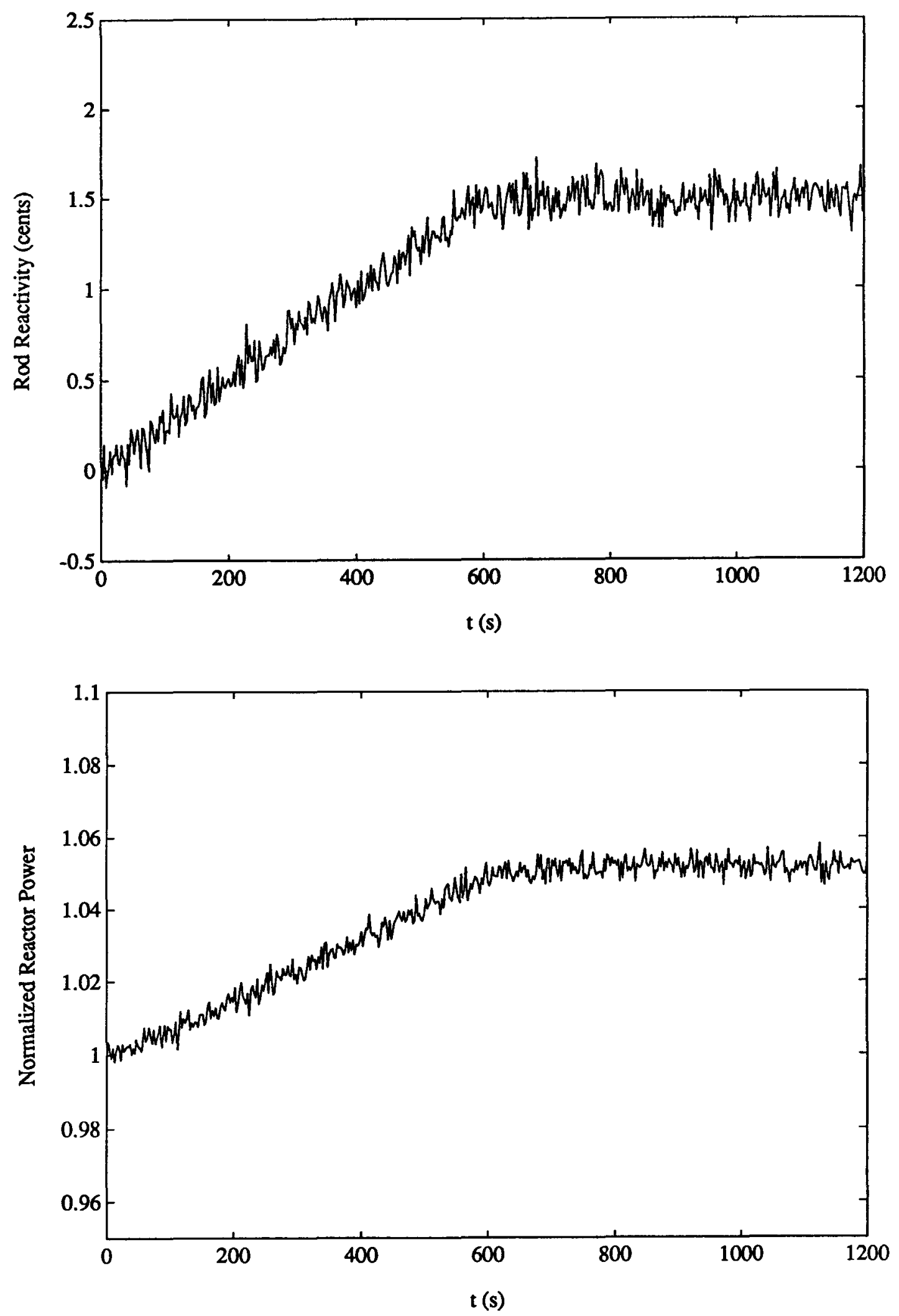

Fig. 4. Simulated Rod Reactivity Perturbation 


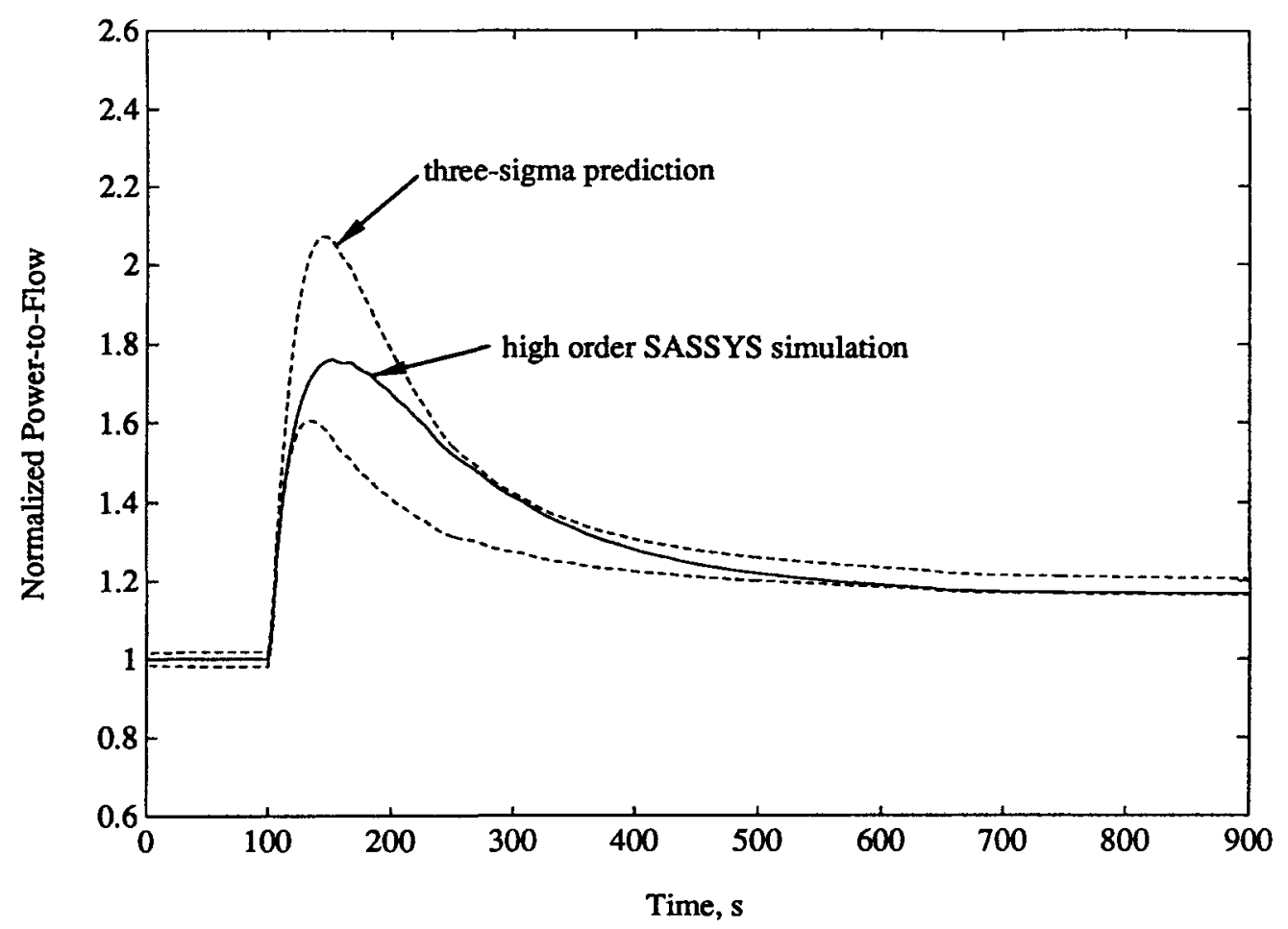

Fig. 5. Simulated Loss of Flow

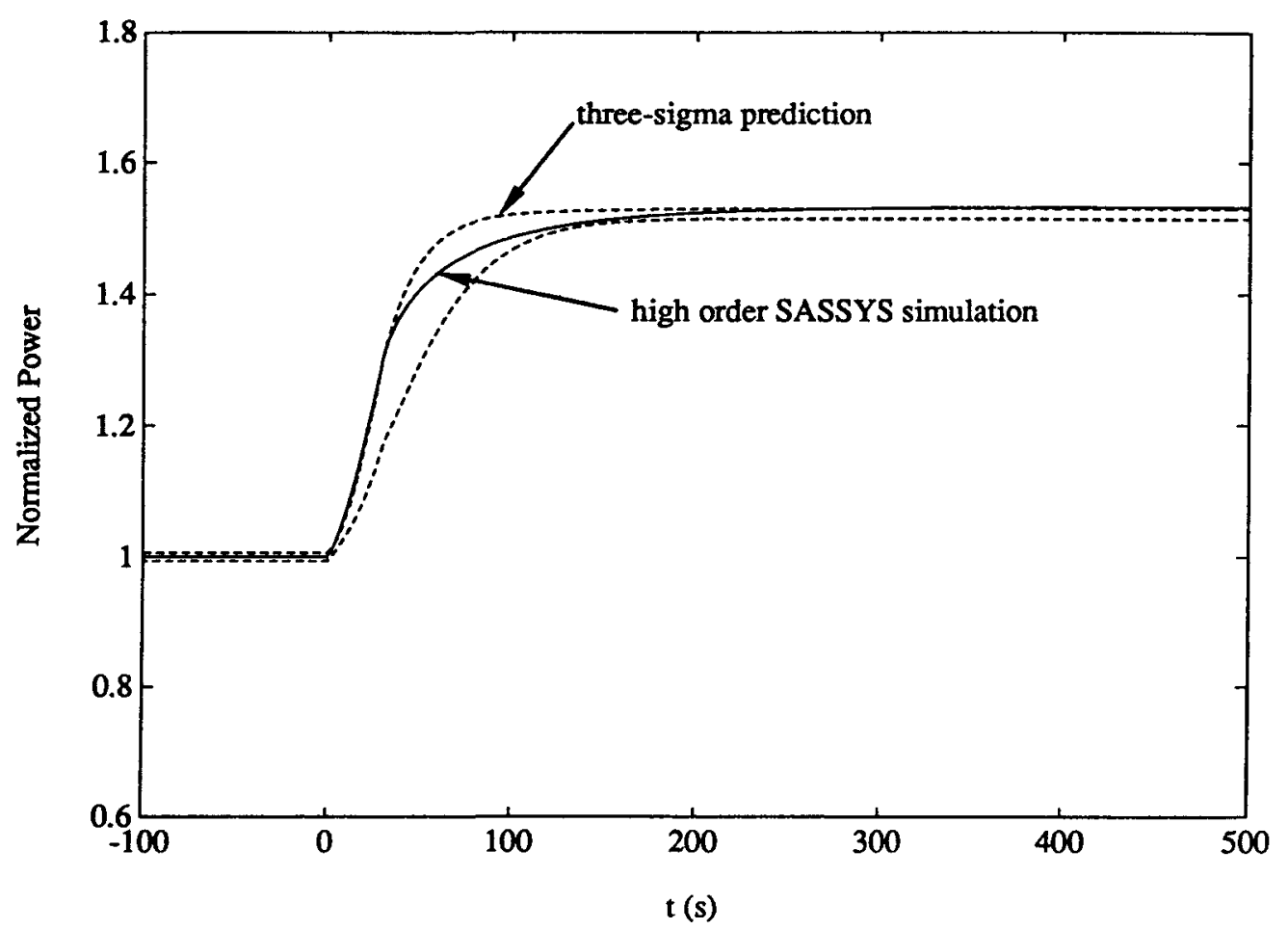

Fig. 6. Simulated Rod Reactivity Insertion 


\section{B. Experiments}

A final assessment of the methodology will take place in EBR-II at which time we will attempt to show that the actual unprotected accident behavior of a plutonium fueled prototype of an IFR core can indeed be predicted from the low-order model identified using the methods in this work. While this demonstration is some time away, groundwork for it has already been laid. The present uranium core is well-understood and physics code estimates exist for all the parameters in Tables II and III. Conversion to a plutonium core will begin in the next one to two years so it is important that the techniques of this report be exercised and proven on the present core. They can then be used with confidence to ensure that the transition core is wellcharacterized. In this subsection we report on some first experiments that were performed during startup of Runs $160 \mathrm{~A}$ and $161 \mathrm{~A}$ in June and October of 1992, respectively. The experiments are derived from Tables II and III and were performed primarily to determine the relationship between the size of a perturbation and the resulting uncertainty in the corresponding parameter. Table VI summarizes the experiments that were performed and the significant findings. The details are described below.

\section{1. $\quad$ Relative Delayed-neutron Fractions}

A rod was dropped at the start of Run $160 \mathrm{~A}$ to measure the relative delayedneutron fractions. The goal was to determine the accuracy to which the values could be measured. Detector efficiency, rod transit time and circuit propagation times can all adversely affect accuracy. Since the core composition is well-known, the delayed-neutron fractions can be calculated from first principles using microscopic cross-section data. The resulting values serve as a reference or independent set of data for comparison.

The number one control rod was dropped from a height of 6 in. inserting about 18 cents of negative reactivity in about $0.45 \mathrm{~s}$. The initial power was $250 \mathrm{kWt}$ so reactivity feedback effects were negligible. The reactor power response and rod position were recorded at $0.01 \mathrm{~s}$ intervals for $1 \mathrm{~min}$ prior to the drop and for $15 \mathrm{~min}$ after. The core inlet temperature 
TABLE VI. Summary of Experiments Performed at Start of Runs 160A and 161A

\begin{tabular}{|c|c|c|c|}
\hline Experiment & Purpose & Significant Findings & Remedial Action \\
\hline $\begin{array}{l}\text { 1. Rod drop } \\
\text { (banked for approach to } \\
\text { power) }\end{array}$ & Measure $\mathrm{a}_{\mathrm{i}}, \mathrm{i}=1, \ldots, \mathrm{n}_{\mathrm{G}}$ & $\begin{array}{l}\text { Good agreement with } \\
\text { VARI3D values }\end{array}$ & \\
\hline $\begin{array}{l}\text { 2. Rod calibration } \\
\text { (banked for approach to } \\
\text { power) }\end{array}$ & Measure $\frac{\mathrm{d} \rho_{\mathrm{j}}}{\mathrm{dx}}(\mathrm{x}) \mathrm{j}=1, \ldots, \mathrm{n}_{\mathrm{ROD}}$ & & \\
\hline $\begin{array}{l}\text { 3. Ascent to power } \\
\text { a. } 80 \% \text { and } 100 \% \text { flow }\end{array}$ & Measure A and B obtrusively & & $\begin{array}{l}\text { Use subassembly } \\
\text { temperature rise to } \\
\text { determine flowrate } \\
\text { change }\end{array}$ \\
\hline b. Again at $100 \%$ flow & Check reproducibility of $\mathrm{A}+\mathrm{B}$ & $\begin{array}{l}\text { Reproducible to } 0.08 \text { cents } \\
(0.3 \%)\end{array}$ & \\
\hline 4. Burnup at power & Measure $\mathrm{d} \rho_{\mathrm{Bu}} / \mathrm{dt}$ & & \\
\hline \multicolumn{4}{|l|}{ 5. Perturbations at power } \\
\hline a. Flowrate change & Measure B/A nonobtrusively & $\begin{array}{l}\text { Inlet temperature variations } \\
\text { compromised determination of } \\
\text { B/A }\end{array}$ & $\begin{array}{l}\text { Install a new inlet } \\
\text { temperature } \\
\text { controller }\end{array}$ \\
\hline b. Rod position change & Measure $\frac{1}{\mathrm{~A}} \frac{\mathrm{d} \rho_{\mathrm{ROD}}}{\mathrm{dx}}$ nonobtrusively & See above & See above \\
\hline c. Inlet temperature change & Measure $\frac{C}{A}$ nonobtrusively & See above & See above \\
\hline
\end{tabular}


was also recorded, but temperature reactivity effects were minimal. Figure 7 is a plot of the channel 7B ion chamber signal.

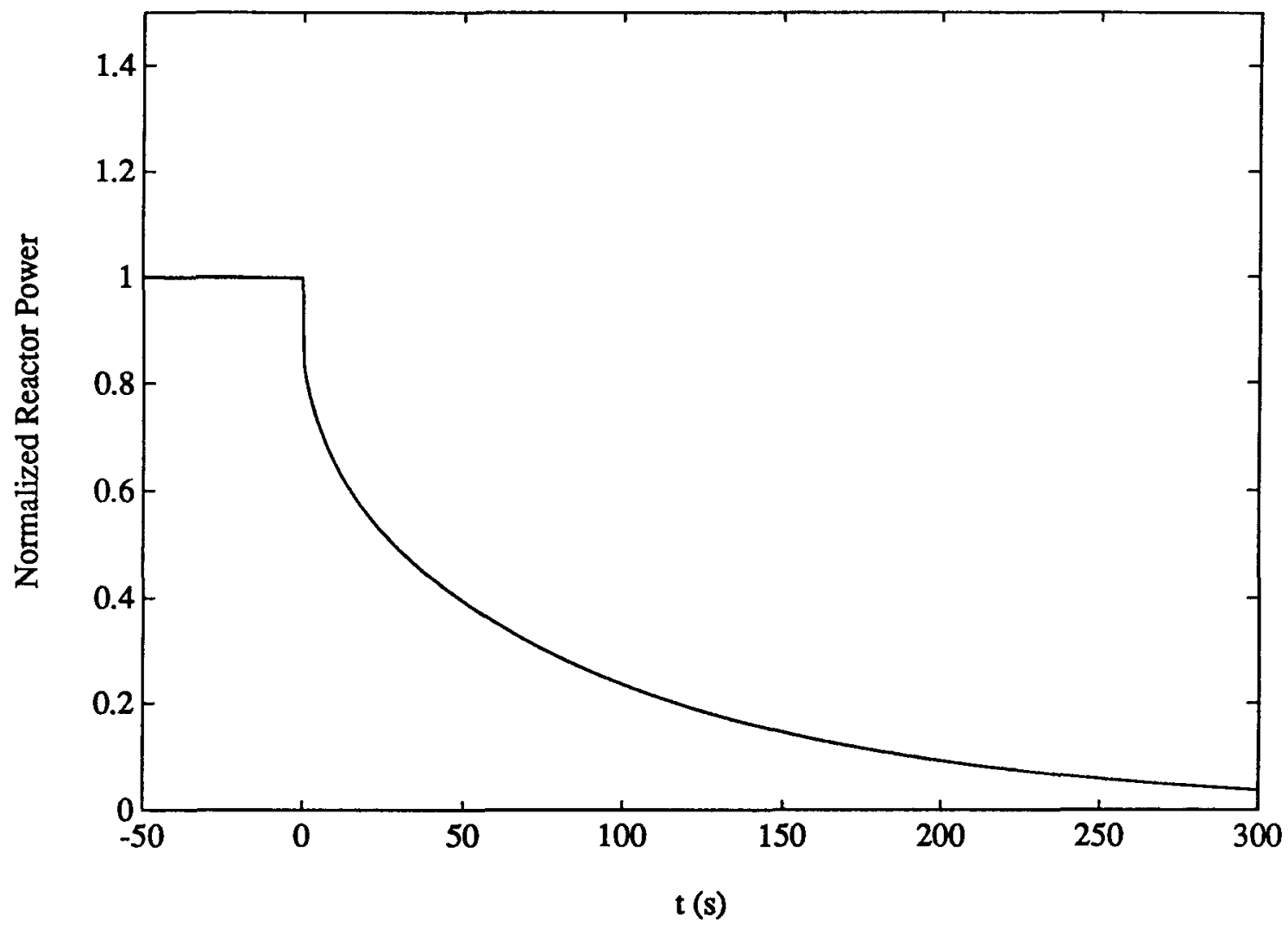

Fig. 7. Flux Die-away from Rod Drop Experiment in EBR-II

The flux die-away was input to the previously described computer code to determine neutron fractions for a given set of decay constants. The results compare very favorably with delayed-neutron data obtained from the VARI3D computer code for Run 160A.[14] VARI3D is a reactor physics code that uses neutron cross section and fission yield data to compute energy spectra, reaction rates and from these the delayed-neutron parameters. Comparison of measured fractions with VARI3D results is shown in Table VII. The greatest error occurs for the fastest precursor, about $20 \%$, but this is not unexpected since the time constant for this precursor is about one half of the rod transit time. Since the least squares fit does not begin until rod motion has stopped, the fastest mode will have all but died out. The remaining measured fractions agree with VARI3D to within a few percent. 
TABLE VII. Relative-delayed Neutron Fractions for Rod Drop of -18 Cents in EBR-II

\begin{tabular}{|c|c|c|c|c|}
\hline \multicolumn{2}{|c|}{$\begin{array}{l}\text { Reference: VARI3D } \\
\text { for Run } 160 A^{\mathrm{a}}\end{array}$} & $\begin{array}{c}\text { Measured at Run } 160 \mathrm{~A} \\
\text { Startup }^{\mathrm{b}}\end{array}$ & $\begin{array}{l}\text { REACT DAS } \\
\text { Values }^{\mathrm{b}}\end{array}$ & $\begin{array}{l}\text { Error: VARI3D } \\
\text { Versus Measured }\end{array}$ \\
\hline$a_{1}$ & 0.0372 & 0.0365 & 0.0345 & $-1.88 \%$ \\
\hline$a_{2}$ & 0.206 & 0.2136 & 0.2040 & $+3.89 \%$ \\
\hline$a_{3}$ & 0.187 & 0.1874 & 0.1851 & $+0.16 \%$ \\
\hline$a_{4}$ & 0.405 & 0.3917 & 0.4023 & $-3.24 \%$ \\
\hline$a_{5}$ & 0.135 & 0.1349 & 0.1409 & $-0.37 \%$ \\
\hline$a_{6}$ & 0.030 & 0.0359 & 0.0331 & $+20.0 \%$ \\
\hline
\end{tabular}

$\begin{array}{lllllll}\text { a } \lambda=0.0127 & 0.0317 & 0.117 & 0.314 & 1.400 & 3.890\end{array}$

$\begin{array}{llllll}\text { b } \lambda=0.0127 & 0.0317 & 0.115 & 0.311 & 1.400 & 3.870\end{array}$

\section{Differential Rod Worths}

Rod motion perturbations were performed at the start of Run 161A to measure rod worths. The perturbations were introduced at a power level of $250 \mathrm{kWt}$ where temperature feedbacks are negligible. The rods were banked for approach to power and then rods were divided into pairs. For a given pair, a first rod was moved up about an inch to induce a power transient. Shortly after motion stopped, the second rod was moved in the same manner in the opposite direction. This sequence was repeated until each rod in the pair had traversed its length.

The differential worth for the rods is obtained by fitting a third-order polynomial in position to the reactivity associated with each of the position changes above. The reactivity change is obtained from Eq. (31). The values of the kinetics parameters in this equation are already known from the rod drop. However, it proved more convenient to perform the rod worth calculation using the set labeled "REACT DAS Values" in Table VII. These values are close enough to the measured values that the error in rod worth is small. The calculated differential rod worths for Rods 4 and 7 are shown in Fig. 8. 

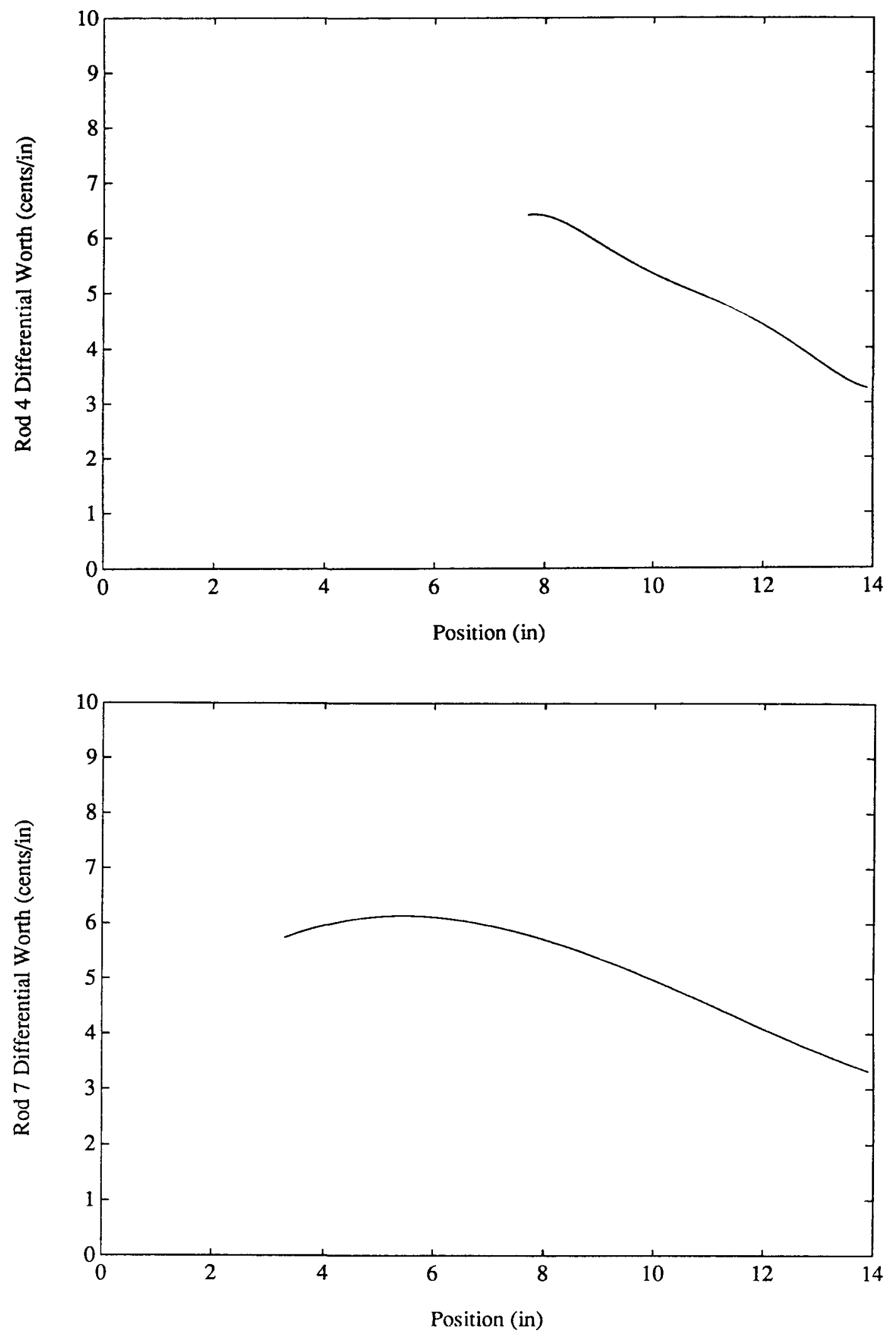

Fig. 8. Differential Rod Worths Measured in EBR-II 


\section{Integral Feedback Parameters from Obtrusive Perturbations}

A goal of the experiments performed at the start of Run 161A was to establish the minimum size of the perturbations needed to obtain parameter values to a given accuracy. Part of this involves performing large perturbations and comparing the parameter values with those from smaller changes. The operating requirements of EBR-II, however, make it difficult to obtain reactor flowrate changes of more than a few percent without shutting down the reactor to make the flowrate change. Thus, the obtrusive flowrate change needed to obtain values for $\mathrm{B}$ and $\mathrm{A}$ required shutting down the reactor.

A potential concern is, however, that shutting down the reactor causes assemblies to unlock and possibly on the return to power to lock in a different mechanical configuration. This could introduce an unwanted component of reactivity. An experiment was conducted to determine the magnitude of this phenomenon. The reactor was taken to full power, shut down and then returned to full power, all at the same flowrate. The difference in the controlling rod position between the two full power conditions after correcting for burnup and inlet temperature variation is the amount of reactivity associated with this phenomenon. This quantity was calculated to be 0.08 cents or $0.3 \%$ of the reactivity needed to get to power. This effect was judged to be small enough that it could be ignored.

An experiment was then performed to measure B and A. The reactor was maintained at several power levels at $80 \%$ flowrate and then after shutting down to change flowrate at several power levels at $100 \%$ flowrate. The data taken are shown in Table VIII. It becomes clear, however, that when the power and flowrate data are normalized to some condition (time 3 in the table), that the normalized power-to-flow ratio is not consistent with the normalized reactor temperature rise. As the table shows, agreement occurs if the $80 \%$ flowrate is adjusted down. One concludes that a bias entered into the percent flowrate instrument when the instrument was setup for operation at $80 \%$ flowrate. Examination of the millivolt signal produced by 512B confirms this. After correcting for this bias and accounting for burnup and inlet temperature variation, a value of -5.93 cents for $A$ and -22.7 cents for $B$ was calculated. 
TABLE VIII. Reactor Data for a Large Flowrate Change to Measure B and A in EBR-II

\begin{tabular}{|c|c|c|c|c|c|c|c|c|c|c|}
\hline \multirow{3}{*}{ Time } & \multicolumn{8}{|c|}{ Unadjusted Data } & \multirow{2}{*}{\multicolumn{2}{|c|}{ Adjusted Data }} \\
\hline & \multicolumn{6}{|c|}{ Measured } & \multicolumn{2}{|c|}{$\begin{array}{l}\text { Normalized (to } \\
\text { time 2) }\end{array}$} & & \\
\hline & $\stackrel{P}{\mathbf{P}}$ & $\begin{array}{l}\mathrm{W} \\
(\%)\end{array}$ & $\begin{array}{c}\mathrm{T}_{\mathrm{i}} \\
\left({ }^{\circ} \mathrm{F}\right)\end{array}$ & $\begin{array}{l}\mathrm{x}_{7}{ }^{\mathrm{a}} \\
\text { (in.) }\end{array}$ & $\begin{array}{c}\Delta \mathrm{T}_{\mathrm{SOT}} \\
\left({ }^{\circ} \mathrm{F}\right)\end{array}$ & $\begin{array}{l}P_{b u} \\
(\mathcal{C})\end{array}$ & $\frac{\mathrm{P} / \mathrm{W}}{(\mathrm{P} / \mathrm{W})_{2}}$ & $\frac{\Delta \mathrm{T}_{\text {SOT }}}{\left(\Delta \mathrm{T}_{\text {SOT }}\right)_{2}}$ & $\begin{array}{l}\delta \mathrm{w} \\
(\%)\end{array}$ & $\frac{\mathrm{P} /(\mathrm{w}+\delta \mathrm{w})}{[\mathrm{P} / \mathrm{w}+\delta \mathrm{w}]_{2}}$ \\
\hline $\begin{array}{c}1 \\
10: 35 \\
10 / 5 / 92\end{array}$ & 40.21 & 99.71 & 701.8 & 9.316 & 117.0 & -0.199 & 0.812 & 0.816 & 0 & 0.812 \\
\hline $\begin{array}{ll}2 & \\
12: 51 & 10 / 5 / 92\end{array}$ & 49.49 & 99.70 & 702.2 & 10.15 & 143.3 & 0 & 1.000 & 1.000 & 0 & 1.000 \\
\hline $\begin{array}{l}3 \\
04: 42 \quad 10 / 3 / 92\end{array}$ & 29.22 & 79.65 & 704.8 & 8.925 & 112.3 & -1.233 & 0.739 & 0.784 & -3.5 & 0.773 \\
\hline $\begin{array}{l}4 \\
06: 56 \quad 10 / 3 / 92\end{array}$ & 38.88 & 79.70 & 704.7 & 10.05 & 146.9 & -1.107 & 0.982 & 1.025 & -3.5 & 1.026 \\
\hline
\end{tabular}

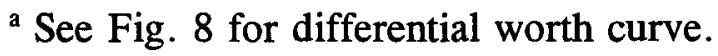




\section{Integral Feedback Parameters from Nonobtrusive Perturbations}

Perturbations were introduced at full power at the start of Run 161A to measure the parameters B/A, $\frac{1}{\mathrm{~A}} \frac{\mathrm{d} \rho}{\mathrm{dx}}$ and C/A of Table III. As shown in Table III, the sequence involves first perturbing reactor flowrate and then solving for B/A. Then rod positions are perturbed to solve for $\frac{1}{\mathrm{~A}} \frac{\mathrm{d} \rho}{\mathrm{dx}}$ given the value of $\mathrm{B} / \mathrm{A}$. Finally, reactor inlet temperature is perturbed to solve for $\mathrm{C} / \mathrm{A}$ given values for $\mathrm{B} / \mathrm{A}$ and $\frac{1}{\mathrm{~A}} \frac{\mathrm{d} \rho}{\mathrm{dx}}$.

The attempt to measure B/A was, however, confounded by changes in the reactor inlet temperature. While the experiment called for inlet temperature to be held constant, the cascade controller was not able to achieve this to the degree that the reactivity associated with inlet temperature change would be second order. Instead, inlet temperature variation introduced an amount of reactivity about one quarter the magnitude of that associated with the flowrate change. The power response, flowrate and inlet temperature are shown in Fig. 9. As the value of C/A had yet to be determined, the inlet temperature reactivity could not be corrected for. Had the inlet temperature variation been second order, then one could iterate among the responses for the three forcing function perturbations until converging to a consistent set of values for $\mathrm{B} / \mathrm{A}$, $\frac{1}{\mathrm{~A}} \frac{\mathrm{d} \rho}{\mathrm{dx}}$ and $\mathrm{C} / \mathrm{A}$.

The attempt to measure $\frac{1}{\mathrm{~A}} \frac{\mathrm{d} \rho}{\mathrm{dx}}$ was similarly confounded. The power response, inlet temperature and rod position changes are shown in Fig. 10.

The attempt to measure C/A failed because its determination is dependent on having values for $\mathrm{B} / \mathrm{A}$ and $\frac{1}{\mathrm{~A}} \frac{\mathrm{d} \rho}{\mathrm{dx}}$. However, since power remained constant, a value of $\mathrm{C}$ could be obtained. The value is -0.348 cents $/{ }^{\circ} \mathrm{F}$. This is the value used to correct for inlet temperature variation in the obtrusive tests described earlier. The power response, inlet temperature and rod position are shown in Fig. 11.

A new reactor inlet temperature controller[15] is being installed to improve the regulation of inlet temperature. The nonobtrusive tests will then be repeated. 

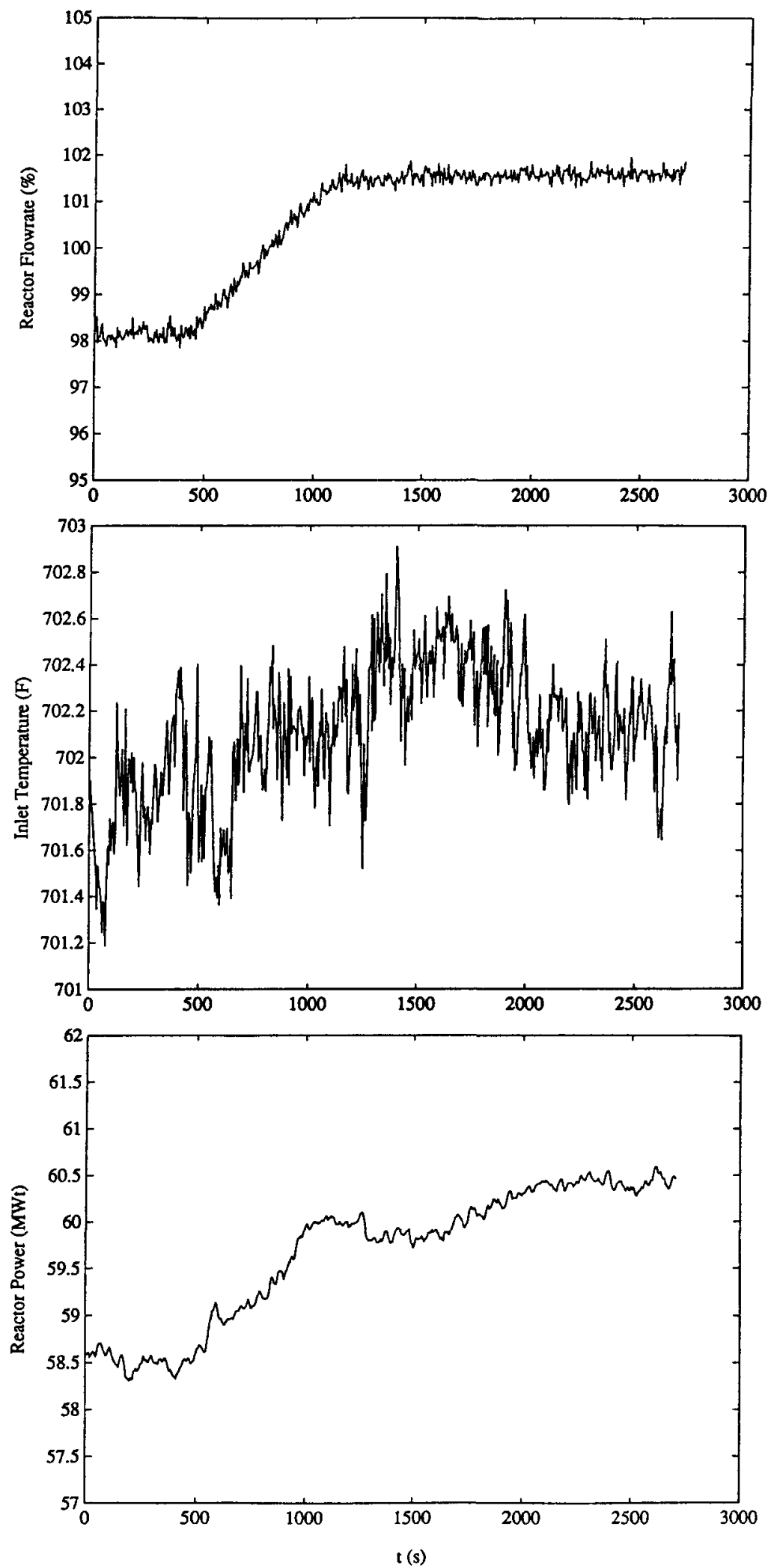

Fig. 9. Reactor Flowrate Perturbation Experiment in EBR-II 

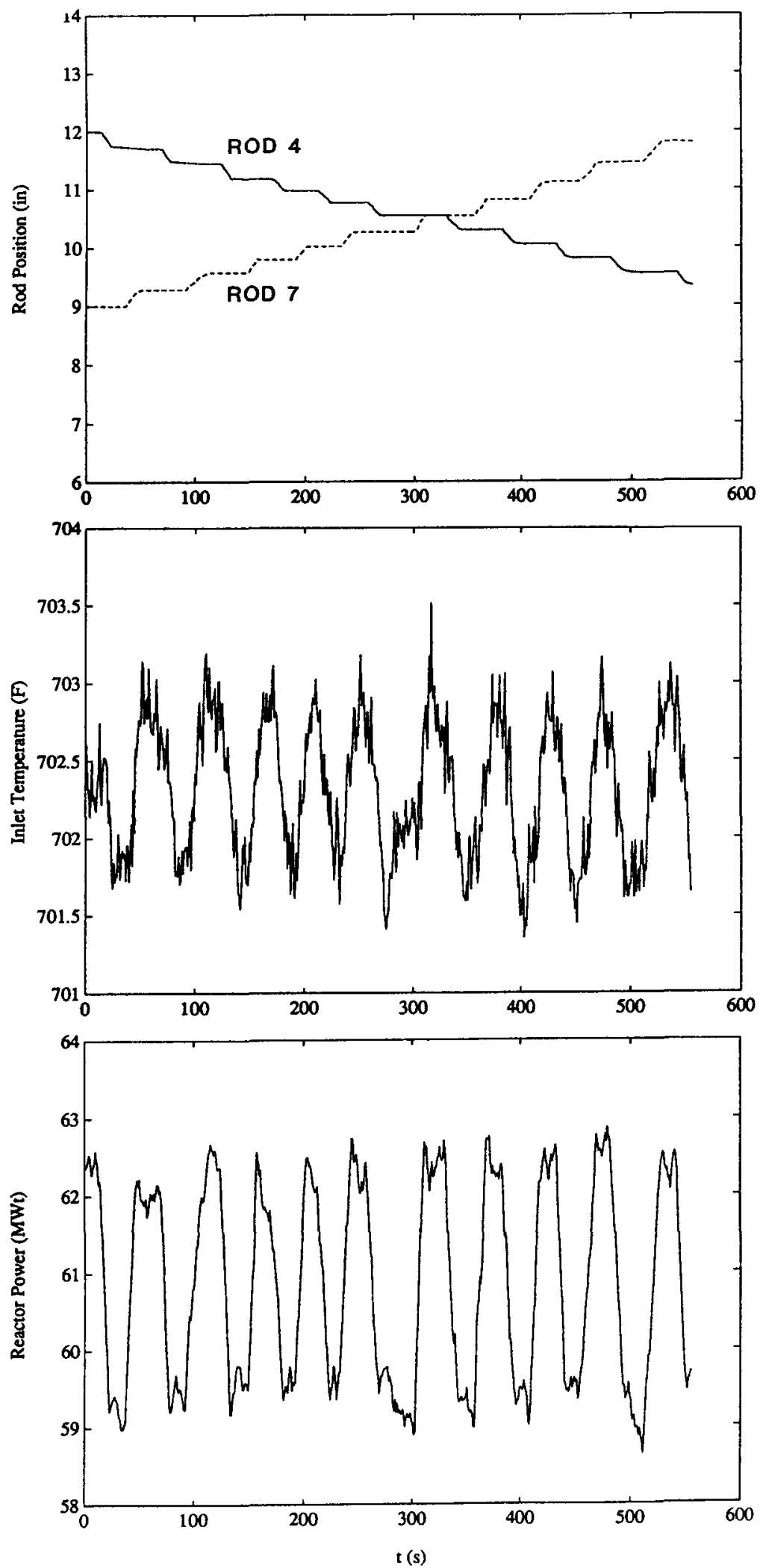

Fig. 10. Control Rod Position Perturbation Experiment in EBR-II 

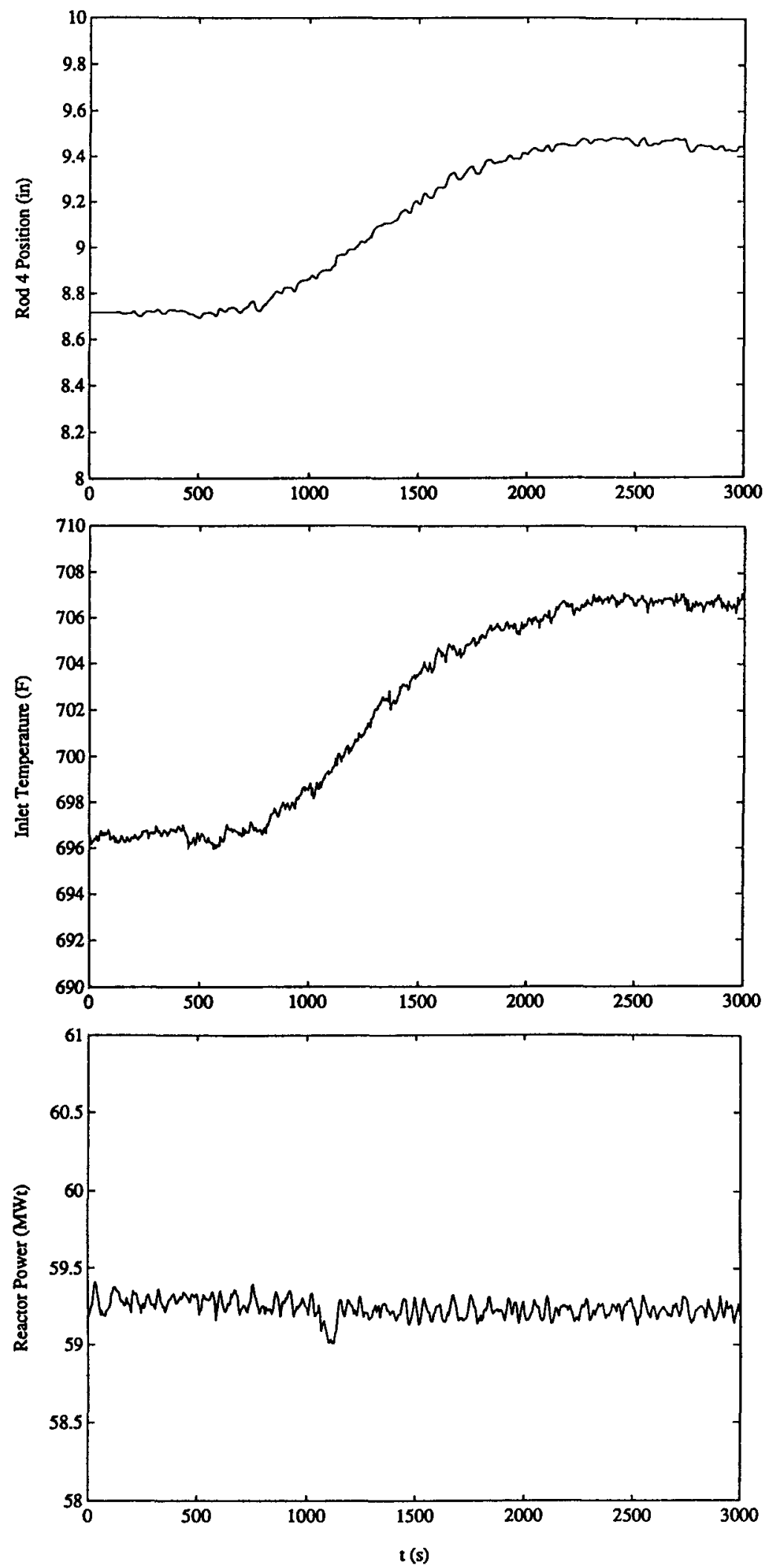

Fig. 11. Reactor Inlet Temperature Perturbation Experiment in EBR-II 


\section{SUMMARY AND CONCLUSIONS}

It has been argued[3,4] that a reactor that has been designed to have passively safe characteristics must also be demonstrably safe if it is to have a role in U. S. energy supply. That is, full-scale demonstration tests must be performed on the integrated power plant to show that the reactor will survive the very severest of tests. Such tests provide incontrovertible evidence of the safety of a design to a licensing body or a sceptical public.

A methodology was described for determining whether a special class of reactors is demonstrably safe. The class consists of those reactors where the same physical mechanisms that control accident behavior also control normal operating behavior thereby allowing for accident behavior to be tested for at normal operation. In the methodology, the underlying physics controlling the fission process and the removal of heat are represented by a model structure whose physics remain valid as long as the reactor geometry is preserved. The specific behavior of a given reactor from a particular class of reactors resides in the values of the parameters in the model. Values for the parameters are obtained at normal operation by perturbing the reactor forcing functions and observing the reactor response. The subsequent model structure and parameter values comprise a measured basis for predicting reactor response, and hence safety, for unprotected accidents.

An assessment of the methodology was performed using simulated reactor data. The SASSYS systems code was used to simulate the EBR-II reactor at startup and noise was added to the forcing functions and reactor response to simulate instrument and process noise. A dropped rod yielded values for the kinetics parameters. Perturbations of rod reactivity and reactor flowrate were introduced to determine values for integral feedback parameters. The identified model was then used to predict the reactor response for loss-of-flow and rod reactivity insertion events. These same forcing functions were used to drive the SASSYS simulation for comparison. The three-sigma response of the identified model enveloped the SASSYS response indicating that off-normal behavior was correctly predicted. 
A limited assessment was also performed using test data from the actual EBR-II reactor. Relative delayed-neutron fractions obtained from a rod drop agreed well with results computed from first principles and basic nuclear data using the VARI3D code. The integral feedback parameters associated with flowrate and rod position changes were measured using large obtrusive changes of these forcing functions and the values obtained were in agreement with accepted values. The measured parameter values served as a reference for comparison with smaller nonobtrusive changes. Unfortunately, the reactor inlet temperature controller was unable to maintain the required precise control of inlet temperature for the nonobtrusive changes. Temperature variations introduced reactivity that could not be accurately compensated for in the analysis. An improved inlet temperature controller is being installed in EBR-II to remedy this problem. This, combined with a power-to-flow trip to permit larger flowrate changes, will improve the prospects for accurately and nonobtrusively measuring integral feedback parameters while at power.

In general, the prospects for predicting unprotected accident response in an IFR reactor appear good. Some simulation work remains to evaluate the degree to which prediction confidence levels can be tightened by going to more than one precursor group. Significant experimental work, however, still remains. Inlet temperature control needs to be improved in EBR-II and, possibly, a power-to-flow trip installed in place of the low flow trip. Finally, lossof-flow and rod runout events need to be performed to complete an experimental assessment of the methodology.

\section{REFERENCES}

1. L. M. Lidsky, "Audiences, Rationales and Quantitative Measures for Demonstrations of Nuclear Safety and Licensing by Tests," Proceedings of the First MIT International Conference on the Next Generation of Nuclear Power Technology, 1:5-2, Massachusetts Institute of Technology, Cambridge, MA (October 1990). 
2. J. Jeyea, "Nuclear Power Public and Utility Acceptance Issues in the United States," Proceedings of the First MIT International Conference on the Next Generation of Nuclear Power Technology, 1:3-2, Massachusetts Institute of Technology, Cambridge, MA (October 1990).

3. R. B. Vilim, "Plant Control Impact on IFR Power Plant Passive Safety Response," presented at Topical Meeting on Nuclear Power Plant Instrumentation, Control and Man-Machine Interface Technologies, 561, Oak Ridge, TN (April 1993).

4. H. P. Planchon, "Implications of the EBR-II Inherent Safety Demonstration Tests, "Nucl. Eng. Des., 101:75-90 (1987).

5. T. J. Moran, "Core Restraint Contributions to Radial Expansion Reactivity, " Proceedings of 1986 Joint ASME/ANS Nuclear Power Conference, 454-458, Philadelphia, PA (July 1986).

6. V. E. Schrock, "A Revised ANS Standard for Decay Heat from Fission Products," Nuc. Technol., 46:323 (1979).

7. L. Ljung, System Identification, Prentice Hall, Englewood Cliffs, NJ (1987).

8. R. L. Morris, "Low Order Model Identification for Drum-Type Power Plant," Report 56, Electric Power Systems Engineering Laboratory, Massachusetts Institute of Technology (1979).

9. F. C. Schweppe, "Evaluation of Likelihood Functions for Gaussian Signals," IEEE Trans. Inform. Theory, IT-11, No. 1 (January 1965).

10. F. C. Schweppe, Uncertain Dynamic Systems, Prentice-Hall, Englewood Cliff, NJ (1975). 
11. D. W. Peterson, Massachusetts Institute of Technology, unpublished data (1976).

12. J. P. Herzog, "SASSYS Validation with the EBR-II Shutdown Heat Removal Tests," Fifth Proceedings of Nuclear Thermal Hydraulics, 1:416, San Francisco, CA (November 25-30, 1989).

13. R. W. Brock and R. B. Vilim, "Measurement of Delayed Neutron Relative Yields from a Rod Drop Flux Die-Away," Argonne National Laboratory, Report ANL-IFR-216 (November 1993).

14. P. J. Finck, Argonne National Laboratory, personal communication (December 1992).

15. R. B. Vilim and H. P. Planchon, "Design of a Reactor Inlet Temperature Controller for EBR-II Using State Space Feedback," Proceedings of the International Fast Reactor Safety Meeting, III:309-18, Snowbird, UT (August 1990).

16. C. K. Chui and G. Chen, Kalman Filtering with Real Time Applications, Springer-Verlag, New York, NY (1987).

\section{ACKNOWLEDGMENTS}

The author gratefully acknowledges the assistance of R. W. Schaeffer, D. Mohr, E. E. Feldman and L. K. Chang during the planning and testing phases of this work and the role played by IFR Operations in ensuring that all planned tests were successfully completed per procedures. 


\section{APPENDIX A \\ LIKELIHOOD FUNCTION FOR A NONLINEAR STOCHASTIC SYSTEM}

This appendix derives an expression for the likelihood function for the nonlinear discrete stochastic system given by Eq. (33),

$$
\underline{\mathbf{x}}(\mathrm{k}+1)=\underline{\mathrm{f}}_{\mathrm{d}}\left[\underline{\mathrm{x}}(\mathrm{k}), \underline{\mathrm{u}}(\mathrm{k}), \underline{\xi}_{\mathrm{u}}(\mathrm{k})\right]+\underline{\xi}_{\mathrm{x}}(\mathrm{k})
$$

and

$$
\underline{y}(\mathrm{k}+1)=\mathrm{g}_{\mathrm{d}}\left[\underline{\mathrm{x}}(\mathrm{k}), \underline{\mathrm{u}}(\mathrm{k}), \underline{\xi}_{\mathrm{u}}(\mathrm{k})\right]+\underline{\mathrm{n}}(\mathrm{k}) .
$$

The derivation of the likelihood function essentially comes down to linearizing Eq. (33) and putting the result in the form of a linear stochastic system. The linearization follows that of Chui[14] and his derivation of the extended Kalman filter equations. Expanding the state update and measurement equations in a Taylor series and dropping all but first-order terms

$$
\begin{aligned}
& f_{i}\left[\underline{x}(k), \underline{u}(k), \underline{\xi}_{u}(k)\right]=f_{i}[\underline{\hat{x}}(k \mid k), \underline{u}(k), 0] \quad i=1, \ldots n \\
& \quad+\left.\sum_{q=1}^{m} \frac{\partial f_{i}}{\partial x_{q}(k)}\right|_{\underline{\hat{x}}(k \mid k), \underline{u}(k), 0}\left[x_{q}(k)-\hat{x}_{q}(k \mid k)\right] \\
& \quad+\left.\sum_{q=1}^{m} \frac{\partial f_{i}}{\partial \xi_{u_{q}}(k)}\right|_{\underline{\hat{x}}(k \mid k), \underline{u}(k), 0} \xi_{u_{q}}(k)
\end{aligned}
$$

and

$$
\begin{aligned}
& \mathrm{g}_{\mathrm{j}}\left[\underline{\mathrm{x}}(\mathrm{k}), \underline{\mathrm{u}}(\mathrm{k}), \underline{\xi}_{\mathrm{u}}(\mathrm{k})\right]=\mathrm{g}_{\mathrm{j}}[\underline{\hat{\mathbf{x}}}(\mathrm{k} \mid \mathrm{k}-1), \underline{\mathrm{u}}(\mathrm{k}), 0] \quad \mathrm{j}=1, \ldots \mathrm{r} \\
& \quad+\left.\sum_{\mathrm{q}=1}^{\mathrm{m}} \frac{\partial \mathrm{g}_{\mathrm{j}}}{\partial \mathrm{x}_{\mathrm{q}}(\mathrm{k})}\right|_{\underline{\hat{\mathbf{x}}}(\mathrm{k} \mid \mathrm{k}-1), \underline{\mathrm{u}}(\mathrm{k}), 0\left[\mathrm{x}_{\mathrm{q}}(\mathrm{k})-\hat{\mathrm{x}}_{\mathrm{q}}(\mathrm{k} \mid \mathrm{k}-1)\right]} \\
& \quad+\left.\sum_{\mathrm{q}=1}^{\mathrm{m}} \frac{\partial \mathrm{g}_{\mathrm{j}}}{\partial \xi_{\mathrm{u}_{\mathrm{q}}}(\mathrm{k})}\right|_{\underline{\hat{\mathbf{x}}}(\mathrm{k} \mid \mathrm{k}-1), \underline{\mathrm{u}}(\mathrm{k}), 0 \underline{\xi}_{\mathrm{u}_{\mathrm{q}}}(\mathrm{k})}
\end{aligned}
$$


Substituting the above equations into Eq. (33) yields

$$
\begin{aligned}
\underline{\mathrm{x}}(\mathrm{k}+1)= & \underline{\mathrm{f}}[\underline{\hat{\mathbf{x}}}(\mathrm{k} \mid \mathrm{k}), \underline{\mathrm{u}}(\mathrm{k}), 0]+\Phi(\mathrm{k})[\underline{\mathrm{x}}(\mathrm{k})-\underline{\hat{\mathbf{x}}}(\mathrm{k} \mid \mathrm{k})] \\
& +\boldsymbol{\Omega}(\mathrm{k}) \underline{\xi}_{\mathrm{u}}(\mathrm{k})+\underline{\xi}_{\mathrm{x}}(\mathrm{k})
\end{aligned}
$$

and

$$
\begin{aligned}
\mathrm{y}(\mathrm{k})= & \mathrm{g}[\underline{\hat{\mathbf{x}}}(\mathrm{k} \mid \mathrm{k}-1), \underline{\mathrm{u}}(\mathrm{k}), 0]+\mathrm{C}(\underline{\mathrm{k}})[\mathrm{x}(\underline{\mathrm{k}})-\hat{\mathrm{x}}(\mathrm{k} \mid \mathrm{k}-1] \\
& +\mathrm{E}(\mathrm{k}) \underline{\underline{u}}_{\mathrm{u}}(\mathrm{k})+\underline{\eta}(\mathrm{k})
\end{aligned}
$$

where the elements of matrices $\Phi, \Omega, C$ and $\mathrm{E}$ are defined as

$$
\begin{array}{ll}
\phi_{i j}(k)=\left.\frac{\partial f_{i}}{\partial x_{j}(k)}\right|_{\underline{\hat{x}}(k \mid k), \underline{u}(k), 0} & \omega_{i j}=\left.\frac{\partial f_{i}}{\partial \xi_{u_{j}}(k)}\right|_{\underline{\hat{x}}(k \mid k), \underline{u}(k), 0} \\
c_{i j}(k)=\left.\frac{\partial g_{i}}{\partial x_{j}(k)}\right|_{\underline{\underline{x}}(k \mid k-1), \underline{u}(k), 0} & e_{i j}=\left.\frac{\partial g_{i}}{\partial \xi_{u j}(k)}\right|_{\underline{\hat{x}}(k \mid k-1), \underline{u}(k), 0 .} .
\end{array}
$$

If we define

$$
\underline{\mathrm{u}}^{\prime}(\mathrm{k})=\underline{\mathrm{f}}[\underline{\hat{\mathrm{x}}}(\mathrm{k} \mid \mathrm{k}), \underline{\mathrm{u}}(\mathrm{k}), 0]-\Phi(\mathrm{k}) \underline{\hat{\mathrm{x}}}(\mathrm{k} \mid \mathrm{k})
$$

and

$$
\underline{y}^{\prime}(k)=\underline{y}(k)-g[\underline{\hat{x}}(k \mid k-1), \underline{u}(k), 0]+C(k) \underline{\hat{x}}(k \mid k-1)
$$

then Eq. (A2) becomes

$$
\underline{\mathrm{x}}(\mathrm{k}+1)=\Phi(\mathrm{k}) \underline{\mathrm{x}}(\mathrm{k})+\underline{\mathrm{u}}^{\prime}(\mathrm{k})+\boldsymbol{\Omega}(\mathrm{k}) \underline{\xi}_{\mathrm{u}}(\mathrm{k})+\underline{\xi}_{\mathrm{x}}(\mathrm{k})
$$

and

$$
\underline{y}^{\prime}(\mathrm{k})=\mathrm{C}(\mathrm{k}) \underline{\mathrm{x}}(\mathrm{k})+\mathrm{E}(\mathrm{k}) \underline{\xi}_{\mathrm{u}}(\mathrm{k})+\underline{\eta}(\mathrm{k})
$$

which is a linear stochastic model form assumed by the Kalman filter algorithm. 
Define

$$
\underline{\hat{x}}(k+1 \mid k)=\underline{f}[\underline{\hat{x}}(k \mid k), \underline{u}(k), 0]
$$

and substitute into Eq. (A3) to get the state update equation

$$
\underline{\hat{x}}(k+1 \mid k)=\Phi(k) \underline{\hat{x}}(k \mid k)+\underline{u}^{\prime}(k) .
$$

Also define

$$
\underline{\hat{x}}(0 \mid 0)=E[\underline{x}(0)], \quad P(0 \mid 0)=\operatorname{Var}[\underline{x}(0)]
$$

and assume that their values are known.

The nonlinear problem has now been linearized. In fact, the linear model, the state update equation and the initial conditions given by Eqs. (A4), (A6) and (A7), respectively, meet the conditions assumed in the linear Kalman filter. It follows that if the state estimate is calculated for $\mathrm{k}=1, \ldots, \mathrm{n}$ from

$$
\begin{aligned}
& P(k \mid k-1)=\Phi(k-1) P(k-1 \mid k-1) \Phi(k-1)^{T}+\Omega(k-1) Q_{u}(k-1) \Omega(k-1)^{T}+Q_{x}(k-1) \\
& \underline{\hat{x}}(k \mid k-1)=\underline{f}[\underline{\hat{x}}(k-1 \mid k-1), \underline{u}(k-1), 0] \\
& G(k)=P(k \mid k-1) C(k)^{T}\left[C(k) P(k \mid k-1) C(k)^{T}+E(k) Q_{u}(k) E(k)^{T}+R(k)\right]^{-1} \\
& P(k \mid k)=[I-G(k) C(k)] P(k \mid k-1) \\
& \underline{\hat{x}}(k \mid k)=\underline{\hat{x}}(k \mid k-1)+G(k)\left[\underline{y}_{m}(k)-g[\underline{\hat{x}}(k \mid k-1), \underline{u}(k), 0]\right]
\end{aligned}
$$

then the estimate has the property

$$
\underline{\mathbf{x}}(\mathbf{n})-\underline{\hat{x}}(\mathbf{n} \mid \mathbf{n}-1) \sim \mathrm{N}[0, \mathrm{P}(\mathrm{n} \mid \mathrm{n}-1)] .
$$


As in the linear case, the likelihood function is written in terms of a measurement residual vector. We define it as

$$
\underline{r}(k)=\underline{y}(k)-\hat{y}(k \mid k-1)
$$

where the measurement estimate is given by

$$
\hat{\mathbf{y}}(\mathrm{k} \mid \mathrm{k}-1)=\mathrm{g}[\underline{\hat{\mathbf{x}}}(\mathrm{k} \mid \mathrm{k}-1), \underline{\mathrm{u}}(\mathrm{k}), 0] .
$$

Substituting the second equation of Eq. (33) into Eq. (A10) gives

$$
\begin{aligned}
\underline{\mathrm{r}}(\mathrm{k})= & \mathrm{g}\left[\underline{\mathrm{x}}(\mathrm{k}), \underline{\mathrm{u}}(\mathrm{k}), \underline{\xi}_{\mathrm{u}}(\mathrm{k})\right]+\underline{\eta}(\mathrm{k}) \\
& -\mathrm{g}[\underline{\mathrm{x}}(\mathrm{k} \mid \mathrm{k}-1), \underline{\mathrm{u}}(\mathrm{k}), 0] .
\end{aligned}
$$

Substituting the second equation of Eq. (A1) into the above equation gives

$$
\underline{\mathrm{r}}(\mathrm{k})=\mathrm{C}(\mathrm{k})[\underline{\mathrm{x}}(\mathrm{k})-\underline{\hat{\mathbf{x}}}(\mathrm{k} \mid \mathrm{k}-1)]+\mathrm{E}(\mathrm{k}) \underline{\xi}_{\mathrm{u}}(\mathrm{k})+\underline{\eta}(\mathrm{k}) .
$$

It follows from Eq. (A9) and the properties of $\underline{\xi}_{u}(\mathbf{k}), \underline{\xi}_{x}(\mathrm{k})$ and $\underline{\eta}(\mathrm{k})$ that $\underline{\mathrm{r}}(\mathrm{k})$ is a Gaussian with mean and variance

$$
\mathrm{E}[\mathrm{r}(\mathrm{k})]=0, \quad \operatorname{Var}[\mathrm{r}(\mathrm{k})]=\sum(\mathrm{k} \mid \mathrm{k}-1)
$$

where

$$
\sum(\mathrm{k} \mid \mathrm{k}-1)=\mathrm{C}(\mathrm{k}) \mathrm{P}(\mathrm{k} \mid \mathrm{k}-1) \mathrm{C}(\mathrm{k})^{\mathrm{T}}+\mathrm{E}(\mathrm{k}) \mathrm{Q}_{\mathrm{u}}(\mathrm{k}) \mathrm{E}(\mathrm{k})^{\mathrm{T}}+\mathrm{R}(\mathrm{k}) .
$$

The probability density function of $\underline{r}(\mathrm{k})$ is then 


$$
\begin{aligned}
& \mathrm{f}[\mathrm{r}(\mathrm{k}) \mid \mathrm{y}(1), \ldots, \mathrm{y}(\mathrm{k}-1)]= \\
& \frac{1}{(2 \pi)^{\mathrm{r} / 2}\left[\operatorname{det} \sum(\mathrm{k} \mid \mathrm{k}-1)\right]^{1 / 2}} \mathrm{e}^{-1 / 2\left[(\mathbf{k})^{\mathrm{T}} \sum(\mathbf{k} \mid \mathrm{k}-1)^{-1} \underline{\mathrm{r}}(\mathbf{k})\right.}
\end{aligned}
$$

where the dependence on $\underline{y}(1), \ldots, \underline{y}(\mathrm{k}-1)$ arises through $\underline{\underline{\hat{x}}}(\mathrm{k} \mid \mathrm{k}-1)$ in Eq. (A15).

Using arguments identical to those in the linear case, the likelihood function can be written as

$$
f[y(1), \ldots, y(n)]=\prod_{k=1}^{n} f[r(k) \mid y(1), \ldots, y(k-1)]
$$

If the plant output measurements are $y_{m}(1), \ldots, y_{m}(n)$, then

$$
\begin{aligned}
& \text { 1n } \mathrm{f}\left[\mathrm{y}_{\mathrm{m}}(1), \ldots, \mathrm{y}_{\mathrm{m}}(\mathrm{n})\right] \\
& =-\frac{1}{2} \sum_{\mathrm{k}=1}^{\mathrm{n}}\left[\underline{\mathrm{r}}_{\mathrm{m}}(\mathrm{k})^{\mathrm{T}} \sum(\mathrm{k} \mid \mathrm{k}-1)^{-1} \underline{\underline{r}}_{\mathrm{m}}(\mathrm{k})+\mathrm{r} \ln 2 \pi+\ln \left|\operatorname{det} \sum(\mathrm{k} \mid \mathrm{k}-1)\right|\right]
\end{aligned}
$$

where

$$
\underline{\mathbf{r}}_{\mathrm{m}}(\mathrm{k})=\underline{\mathbf{y}}_{\mathrm{m}}(\mathrm{k})-\mathrm{g}[\underline{\hat{\mathbf{x}}}(\mathrm{k} \mid \mathrm{k}-1), \underline{\mathbf{u}}(\mathrm{k}), 0] .
$$




\section{APPENDIX B}

\section{ASYMPTOTIC PROPERTIES OF THE MEASUREMENT RESIDUAL MATRICES}

The statistical properties of the measurement residual matrices defined by Eq. (43) are derived in this appendix. Use is made of the fact that the errors in the Kalman filter state estimate form a white sequence. Specifically,

$$
\begin{aligned}
\mathrm{E}[\underline{\mathrm{x}}(\mathrm{k})-\underline{\hat{\mathrm{x}}}(\mathrm{k} \mid \mathrm{k}-1)]=0 & \\
\mathrm{E}\left[(\underline{\mathrm{x}}(\mathrm{k})-\underline{\hat{\mathrm{x}}}(\mathrm{k} \mid \mathrm{k}-1))(\underline{\mathrm{x}}(\mathrm{k}+1)-\underline{\hat{\mathrm{x}}}(\mathrm{k}+\mathrm{q} \mid \mathrm{k}-1+\mathrm{q}))^{\mathrm{T}}\right] & =\mathrm{P}(\mathrm{k} \mid \mathrm{k}-1), \mathrm{q}=0 \\
& =0 \quad, \mathrm{q} \neq 0 .
\end{aligned}
$$

From this result and Eq. (A12), it follows that the measurement residuals are also a white sequence

$$
\mathrm{E}[\underline{\mathrm{r}}(\mathrm{k})]=0
$$

and

$$
\begin{aligned}
\mathrm{E}\left[\underline{\mathrm{r}}(\mathrm{k}) \underline{\mathrm{r}}(\mathrm{k}+\mathrm{q})^{\mathrm{T}}\right] & =\Sigma(\mathrm{k} \mid \mathrm{k}-1), & \mathrm{q}=0 \\
& =0, & \mathrm{q} \neq 0 .
\end{aligned}
$$

The first step toward determining the statistical properties of $R(q)$ for our nonlinear system is to determine the properties of the normalized measurement residuals $\underline{\tilde{r}}(\mathrm{k})$. Specifically, we seek $E\left[\underline{\tilde{r}}(\mathrm{k}) \tilde{\tilde{r}}(\mathrm{k}+q)^{\mathrm{T}}\right]$ and $\operatorname{Var}\left[\underline{\tilde{r}}(\mathrm{k}) \underline{\tilde{r}}(\mathrm{k}+q)^{\mathrm{T}}\right]$. We have from Eqs. (B1) and Eq. (44) and the fact that $\Sigma(\mathrm{k} \mid \mathrm{k}-1)$ is symmetric and that $\underline{\mathrm{r}}(\mathrm{k})$ are uncorrelated in time that

$$
\mathrm{E}[\underline{\tilde{r}}(\mathrm{k})]=0
$$

and

$$
\begin{aligned}
\mathrm{E}\left[\underline{\tilde{\mathrm{r}}}(\mathrm{k}) \underline{\tilde{\mathrm{r}}}(\mathrm{k}+\mathrm{q})^{\mathrm{T}}\right] & =\Sigma(\mathrm{k} \mid \mathrm{k}-1)^{-1 / 2} \mathrm{E}\left[\underline{\mathrm{r}}(\mathrm{k}) \underline{\mathrm{r}}(\mathrm{k}+\mathrm{q})^{\mathrm{T}}\right] \Sigma(\mathrm{k}+\mathrm{q} \mid \mathrm{k}-1+\mathrm{q})^{-1 / 2} \\
& =\mathrm{I} \delta_{\mathrm{k}, \mathrm{k}+1}
\end{aligned}
$$


That $\underline{\tilde{r}}(\mathbf{k})$ is a Gaussian is implied by Eqs. (A9) and (A12). The pdf of $\underline{\tilde{r}}(\mathbf{k})$ is then

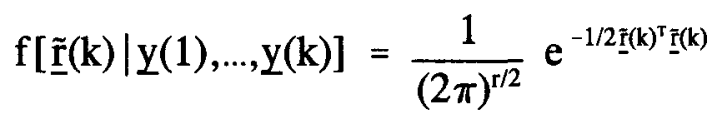

where the mean and variance were taken from Eqs. (B2) and (B3). The above equation can be expanded to give

$$
\mathrm{f}[\underline{\tilde{\mathbf{r}}}(\mathrm{k}) \mid \mathrm{y}(1), \ldots, \underline{\mathrm{y}}(\mathrm{k})]=\prod_{\mathrm{i}=1}^{\mathrm{r}} \frac{1}{\sqrt{2 \pi}} \mathrm{e}^{-1 / 2 \underline{\underline{\mathrm{g}}(\mathrm{k}))_{1}^{2}}}
$$

where $\underline{\tilde{r}}(\mathbf{k})_{i}$ is the ith element of $\underline{\tilde{r}}(\mathbf{k})$. The above equation implies that

$$
\mathrm{f}\left[\underline{\tilde{\mathbf{r}}}(\mathrm{k})_{\mathrm{i}} \mid \mathrm{y}(1), \ldots, \underline{\mathrm{y}}(\mathrm{k})\right]=\frac{1}{\sqrt{2 \pi}} \mathrm{e}^{-1 / 2 \tilde{\mathrm{I}}(\mathrm{k})_{\mathrm{i}}^{2}}
$$

that is,

$$
\underline{\tilde{\mathbf{I}}}(\mathrm{k})_{\mathrm{i}} \sim \mathrm{N}(0,1) .
$$

We are now ready to determine $\operatorname{Var}\left[\tilde{\tilde{r}}(\mathbf{k}) \underline{\tilde{r}}(k+q)^{\mathrm{T}}\right]$. For the case where $q$ is not zero, the ijth element is

$$
\begin{aligned}
& \operatorname{Var}\left[\underline{\tilde{r}}(k)_{j} \underline{\tilde{r}}(k+q)_{j}\right]=\int_{-\infty}^{\infty} d \underline{\tilde{r}}(k)_{i} \int_{-\infty}^{\infty} d \underline{\tilde{r}}(k+q)_{j} \\
& \left\{\underline{\tilde{\mathbf{r}}}(\mathbf{k})_{i} \tilde{\tilde{r}}(k+q)_{j}-E\left[\tilde{r}(k)_{i} \underline{\tilde{r}}(k+q)_{j}\right\}^{2} f\left[\tilde{r}(k)_{i}\right] f\left[\tilde{r}(k+q)_{j}\right]\right.
\end{aligned}
$$


The above equation simplifies to

$$
\operatorname{Var}\left[\underline{\tilde{r}}(k)_{i} \underline{\tilde{r}}(k+q)_{j}\right]=\left\{\int_{-\infty}^{\infty} d \underline{\tilde{r}}(k)_{i} \underline{\tilde{r}}(k)_{i}^{2} f\left[\underline{\tilde{r}}(k)_{i}\right]\right\}^{2}=1
$$

after using Eq. (B3) and the fact that each element of $\underline{\tilde{r}}(k)$ is independent of each element of $\underline{\tilde{\underline{r}}}(\mathrm{k}+1)$ but all have the same distribution. For the case where $q$ is equal to zero, the ijth off-diagonal element is

$$
\begin{aligned}
& \operatorname{Var}\left[\underline{\tilde{r}}(k)_{i} \underline{\tilde{\mathbf{I}}}(\mathbf{k})_{j}\right]=\int_{-\infty}^{\infty} \mathrm{d} \underline{\tilde{r}}(k)_{i} \int_{-\infty}^{\infty} d \underline{\tilde{r}}(k)_{j}
\end{aligned}
$$

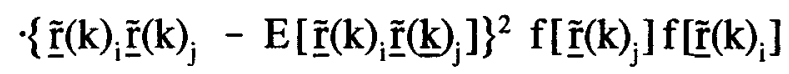

This equation simplifies to

$$
\operatorname{Var}\left[\tilde{\underline{r}}(\mathbf{k})_{i} \tilde{\mathbf{r}}(\mathbf{k})_{j}\right]=1
$$

after the use of Eq. (B3). For the diagonal elements

$$
\operatorname{Var}\left[\underline{\tilde{\mathbf{r}}}(\mathbf{k})_{i}^{2}\right]=\int_{-\infty}^{\infty} \mathrm{d} \underline{\tilde{r}}(k)_{i}\left\{\tilde{\tilde{r}}(k)_{i}^{2} E\left[\tilde{r}(k)_{i}\right]^{2}\right\}^{2} f\left[\underline{\tilde{r}}(k)_{i}\right]
$$

which upon substitution of Eq. (B3) and expansion becomes

$$
\begin{aligned}
\operatorname{Var}\left[\underline{\tilde{r}}(k)_{i}^{2}\right] & =\int_{-\infty}^{\infty} d \underline{\tilde{r}}(k)_{i}\left\{\tilde{\tilde{r}}(k)_{i}^{4}-2 \tilde{\mathbf{r}}(k)_{i}+1\right\} f\left[\tilde{\tilde{r}}(\mathbf{k})_{\mathrm{i}}\right] \\
& =3-2+1 \\
& =2 .
\end{aligned}
$$


To summarize,

$$
\begin{aligned}
& \mathrm{E}[\underline{\tilde{r}}(\mathrm{k}) \underline{\tilde{\mathbf{r}}}(\mathrm{k}+\mathrm{q})]=I \delta_{\mathrm{k}, \mathrm{k}+\mathrm{q}}, \\
& \operatorname{Var}\left[\underline{\tilde{r}}(\mathrm{k}) \underline{\tilde{r}}(\mathrm{k})^{\mathrm{T}}\right]=\left[\begin{array}{cccc}
2 & 1 & \ldots & 1 \\
1 & 2 & & \vdots \\
\ldots & 2 & 1 \\
1 & \ldots & 1 & 2
\end{array}\right] \text {, and } \\
& \operatorname{Var}\left[\underline{\tilde{r}}(\mathbf{k}) \underline{\tilde{\mathbf{r}}}(\mathbf{k}+1)^{\mathrm{T}}\right]=\left[\begin{array}{cccc}
1 & 1 & \ldots & 1 \\
1 & 1 & \cdot & . \\
: & \cdot & 1 & 1 \\
1 & \ldots & 1 & 1
\end{array}\right], \mathrm{q} \neq 0 \text {. }
\end{aligned}
$$

We can now return to $R(q)$ defined by

$$
R(q)=\frac{1}{N-1} \sum_{k=1}^{N-1} \tilde{\tilde{\underline{r}}}(\mathbf{k}) \underline{\tilde{r}}(\mathrm{k}+\mathrm{q})^{\mathrm{T}}
$$

Each diagonal element of $\mathrm{R}(0)$ is a sum of $\mathrm{N} \chi^{2}$ variables since $\underline{\tilde{r}}(\mathrm{k})$ is unit normal. Thus $\mathbf{N}$ $\mathrm{R}(0)_{\mathrm{ii}}$ must be $\mathrm{N} \chi^{2}$ which has mean $\mathrm{N}$ and variance $2 \mathrm{~N}$ so that $\mathrm{R}(0)_{\mathrm{ii}}$ has mean 1 and variance 2.

To summarize 
$-57-$

$$
\begin{aligned}
& \mathrm{E}[\mathrm{R}(\mathrm{q})]=\mathrm{I} \delta_{0, \mathrm{q}} \text {, } \\
& \operatorname{Var}[R(0)]=\left[\begin{array}{llll}
2 & 1 & \ldots & 1 \\
1 & 2 & & : \\
. & & 2 & 1 \\
1 & \ldots & 1 & 2
\end{array}\right] \text { and } \\
& \operatorname{Var}[R(q)]=\left[\begin{array}{cccc}
1 & 1 & \ldots & 1 \\
1 & 1 & \cdot & \cdot \\
\vdots & \cdot & 1 & 1 \\
1 & \ldots & 1 & 1
\end{array}\right], \mathbf{q} \neq 0
\end{aligned}
$$

